\title{
EQUITY-ORIENTED INSTRUCTOR PERSPECTIVES ON TEACHING DEVELOPMENTAL ENGLISH IN THE COMMUNITY COLLEGE
}

\author{
A dissertation submitted to the faculty of \\ San Francisco State University \\ $\begin{array}{ll}35 & \text { In partial fulfillment of } \\ 2019 & \text { The Requirements for }\end{array}$ \\ EDD The Degree \\ .$C 38$ \\ Doctor of Education \\ In \\ Educational Leadership
}

by

Sheryl Anne Cavales Doolan

San Francisco, California

August 2019 


\section{Copyright by}

Sheryl Anne Cavales Doolan 2019 


\section{EQUITY-ORIENTED INSTRUCTOR PERSPECTIVES}

\section{CERTIFICATION OF APPROVAL}

I certify that I have read Equity-Oriented Instructor Perspectives on Teaching Developmental English in the Community College by Sheryl Anne Cavales Doolan, and that in my opinion this work meets the criteria for approving a dissertation submitted in partial fulfillment of the requirements for

the degree: Doctor of Education in Educational Leadership at San Francisco State University.

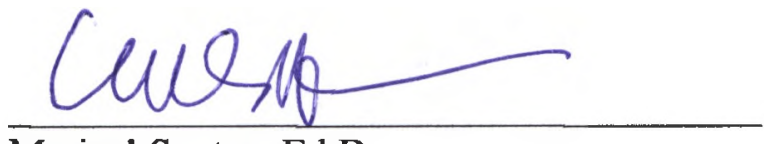

Maricel Santos, Ed.D

Professor of English

San Francisco State University

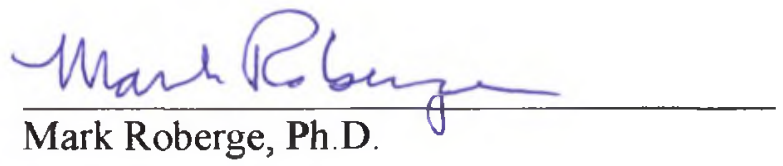

Professor of English

San Francisco State University

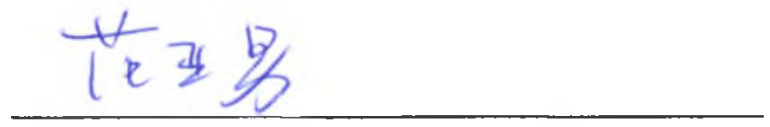

Yanan Fan, Ph.D.

Professor of Secondary Education

San Francisco State University 


\title{
EQUITY-ORIENTED INSTRUCTOR PERSPECTIVES ON TEACHING DEVELOPMENTAL ENGLISH IN THE COMMUNITY COLLEGE
}

\author{
Sheryl Cavales Doolan \\ San Francisco State University \\ 2019
}

As a result of $\mathrm{AB} 705$ mandates, which reforms placement practices and reduces developmental pathways in Math and English in an effort to improve educational inequity, the majority of incoming students in California community colleges will now be placed directly into the college-level composition course. Understanding the perspective of developmental English instructors who intentionally attend to equity issues can be a vital resource for instructors of freshman composition. This study sought to understand how equity-oriented developmental English instructors conceptualize equity and describe their equity-oriented teaching practices. Data sources include two interviews, instructor-generated course materials (e.g. syllabi, essay prompts, and grading rubrics), as well as researcher field notes and data memos. The study followed an embedded case study research design, using a "ground-up," constant comparative analytical methodology. Three major findings emerged from the data analysis: 1) participants conceptualized equity-oriented pedagogy in terms of student empowerment; 2) participants perceived equity-oriented pedagogy as being enmeshed with - and often in opposition to departmental discussions of rigor; and 3) participants described the integration of equityoriented pedagogy within the context of the department as being contentious. The findings of this study reveal that meaningfully promoting equity-oriented practices requires acknowledgment of how equity plays out both in classroom instruction and in departmental discourse.

I certify that the Abstract is a correct representation of the content of this dissertation.

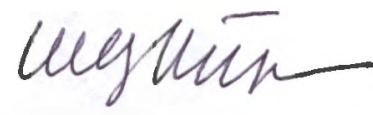

Chair, Dissertation Committee

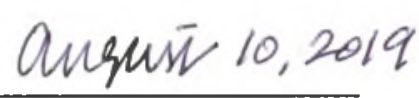

Date 


\section{ACKNOWLEDGEMENTS}

For my daughters, Leelu and Karina, as they embark on their own educational odyssey. And for Auntie Ping - I wish you could see me now.

Thank you to my committee, Dr. Maricel Santos, Dr. Mark Roberge, and Dr. Yanan Fan. Your support, patience, amazing feedback, and guidance through this process has not only helped improve this dissertation, but it also has helped me reflect more on my work as an educator and compositionist.

Thank you to the Get It Done crew. Your online and real-life company kept me on task, focused, in good humor, and (reasonably) sane. Special thanks to critical colleagues and dear friends, Dr. Samyalisa Enright and Dr. Mallory Stevens. It's been a great honor.

Thank you to all of my family, who have sacrificed so much throughout the doctoral program and the dissertation writing. Thank you for the childcare, for last-minute meals, for your patience when I cancelled plans, for retail therapy, 
for cheerleading videos, for motivational memes and Supernatural gifs...for more than I could ever ask for or retum. I am truly blessed.

And finally, thank you to my husband, Dr. Daniel Doolan. You have been a critical colleague, therapist, sounding board, ideas man, and dissertation Sherpa. Thank you for your unflagging, unfailing belief in me, especially when I didn't have faith in myself. I'm grateful beyond words. Go, Team Doolan! 


\section{TABLE OF CONTENTS}

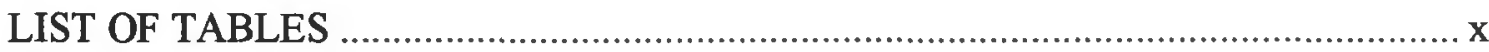

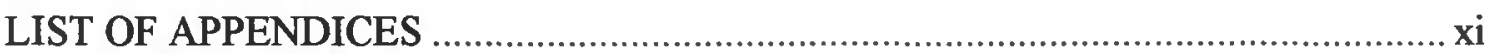

Chapter One: Purpose of the Study ................................................................... 1

The Backdrop of Inequity ......................................................................... 4

Purpose of the Study and Research Questions .............................................. 8

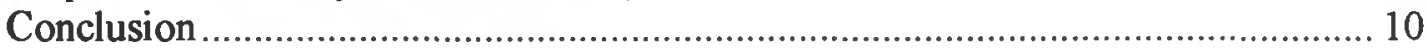

Chapter Two: Literature Review .............................................................. 12

AB705 and "The Completion Agenda" .................................................... 13

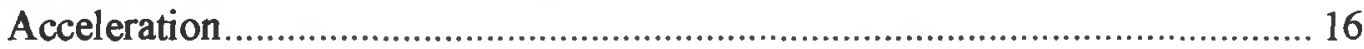

Pragmatic Equity-Driven Practices - Universal Design for Learning .............. 21

Culturally Relevant, Culturally Responsive, and Culturally Sustaining Pedagogies........................................................................................... 23

Learning Communities - The Puente Program ............................................ 24

Equity-mindedness in Instruction ....................................................... 26

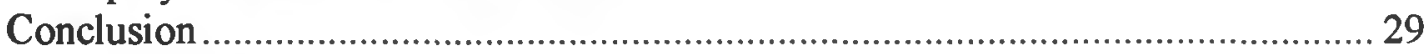

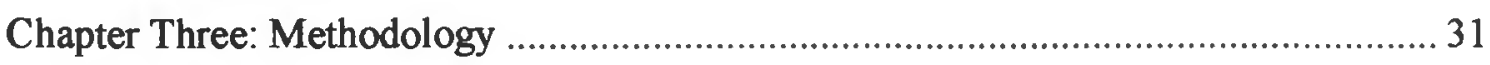

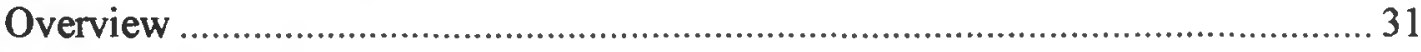

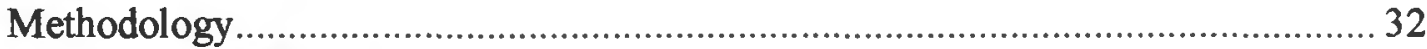

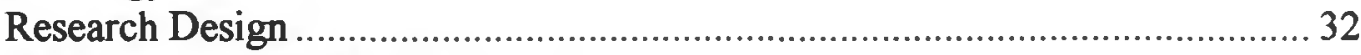

The Case: The NCCC English Department................................................. 32

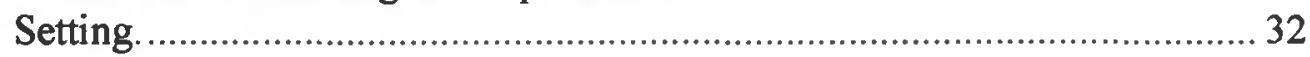

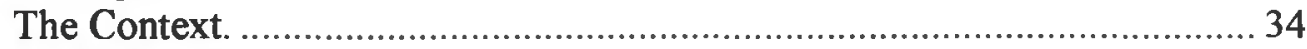

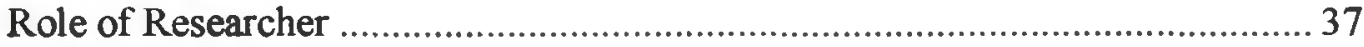

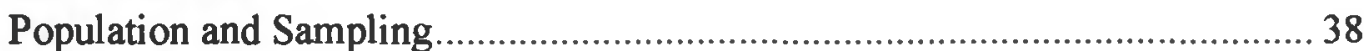

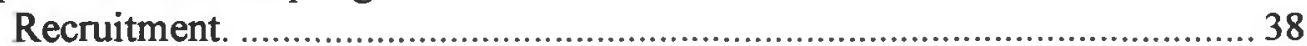

Selection criteria

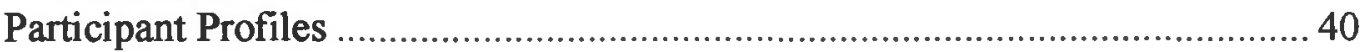

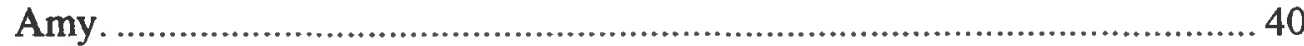

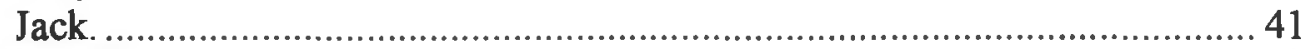

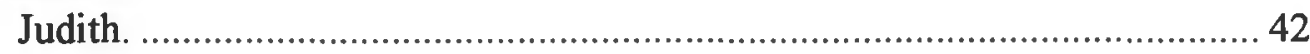

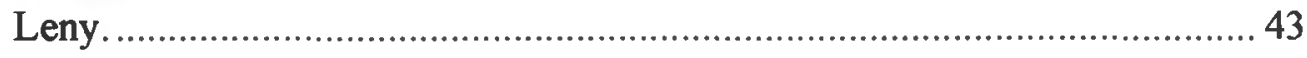




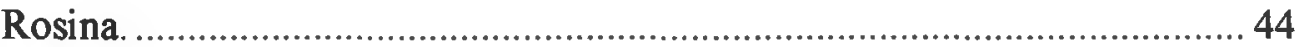

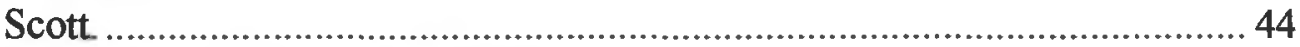

Statement of Ethical Considerations ............................................................ 45

Data Collection Procedures ........................................................................... 46

Data Analysis Procedures............................................................................ 48

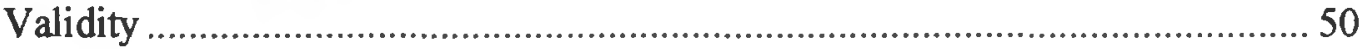

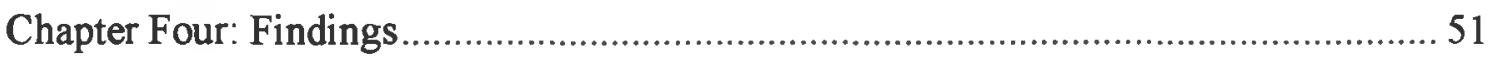

Overview

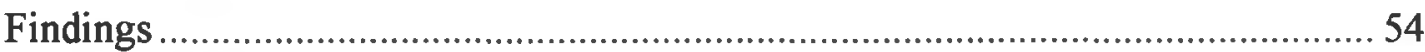

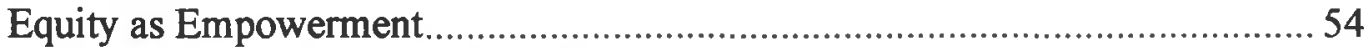

Enacting culturally relevant pedagogy...................................................... 55

Humanizing feedback through in-person writing conferences......................58

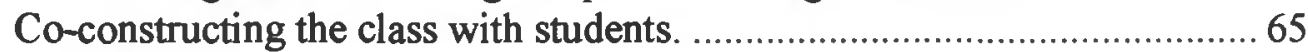

The Relationship of Equity to Perceptions of Rigor ..........................................69

Critiquing rigor as being rigid. ............................................................... 71

Critiquing rigor as achieving correctness in "standard English."................. 73

Critiquing rigor as suffering. ................................................................... 76

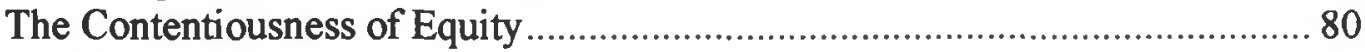

Mixed feelings about AB705's potential for change .................................. 82

The necessity of addressing racial inequity ...............................................8 86

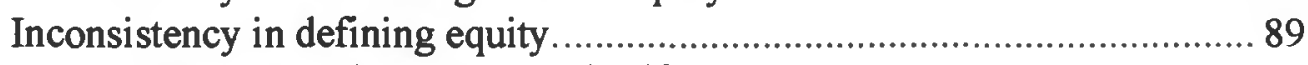

Resolving tensions through critical self-reflection...................................... 94

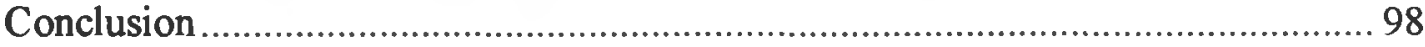

Chapter Five: Implications and Recommendations ................................................. 99

Overview of Study

Summary Discussion of Findings .......................................................................... 101

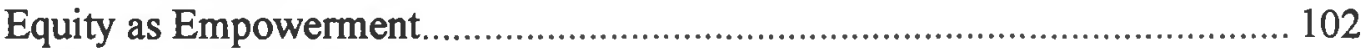

The Relationship of Equity to Perceptions of Rigor ....................................... 103

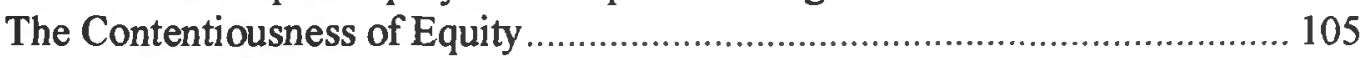

Implications and Recommendations............................................................... 106

Recommendations for Community College English Instructors....................... 106

Use culturally relevant curriculum with a holistic, humanist approach. .... 107

Center relationships and community building in the classroom. ............... 108

Create opportunities to practice critical self-reflection. ............................. 109

Recommendations for English Faculty Leaders ............................................... 110

Define critical issues.................................................................................. 111

Create opportunities for critical self-reflection for faculty........................ 111

Recommendations for College Leaders...................................................... 112

Recommendations for Pre-Service Training Programs for Writing Teachers . 112 
Recommendations for Further Study ......................................................... 113

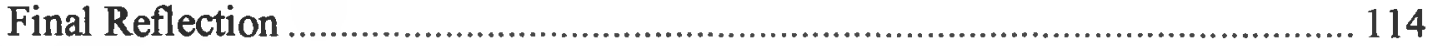

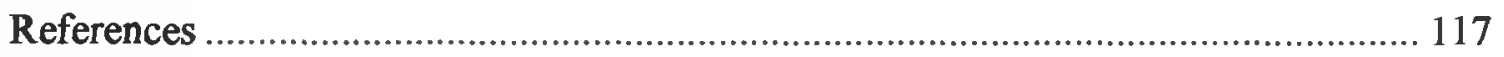

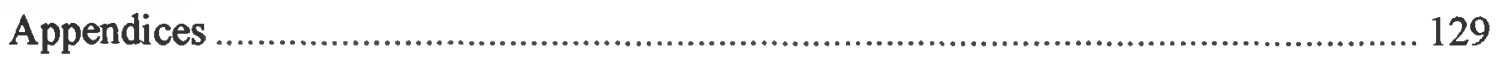

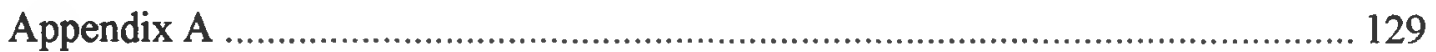

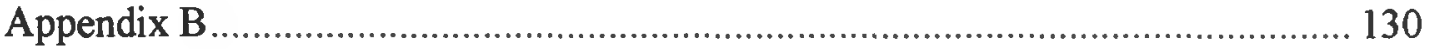

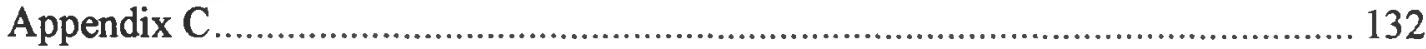




\section{LIST OF TABLES}

Table

Page

1. Demographic information of participants

38

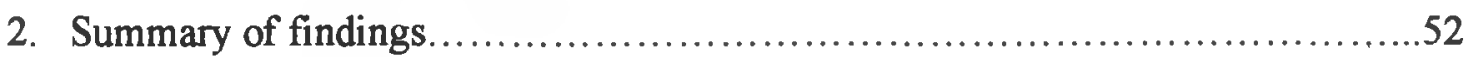




\section{LIST OF APPENDICES}

Appendix

Page

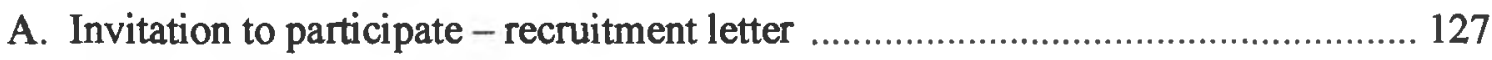

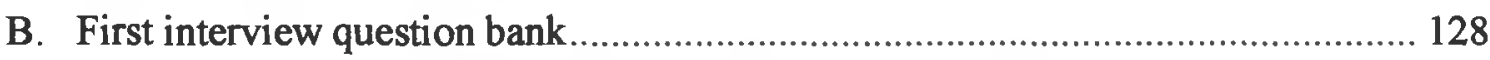

C. Representative sample of question bank for second interview protocol.......... 130 


\section{Chapter One: Purpose of the Study}

I am a multiracial woman who grew up in predominantly White environments. When my father immigrated from the Philippines, settling in the Pacific Northwest at the age of 32 , he did what many immigrants of his time did: embraced White American culture in an effort to escape discrimination and racial hostility through assimilation. My mother, herself a daughter of a Greek immigrant, had little experience with racism as a White woman growing up in Texas. However, the poverty she and her six siblings grew up in drove her to work hard and motivated her to raise her class standing. For these parents, education was the great equalizer and the key to a bright future. The "equalizing" effect, however, was not benign. Equalizing meant assimilation; it meant reading a single paragraph in a history textbook about the Filipinos' role in ending World War II reduced to being "the little brown brothers" of American soldiers. Equalizing meant learning everything from history to English to math from a white perspective, where the term "minorities" always referred to "others," never "us." Being half White and half Filipina, I both belonged and didn't belong. It wasn't until our family moved to Northern California, where I attended junior and high schools that had far more ethnic diversity in students and where I first had teachers of color, that I began to see how it was possible for education to reflect my life experience and family culture.

My early education influenced my later experience as a graduate student in the California State University system. I was enrolled in the Master's in English program, 
with a special emphasis in Rhetoric and the Teaching of Writing. Despite my university being a predominantly White institution in a mostly White, affluent county, I was fortunate to have professors who valued critical pedagogy and who made texts like Pedagogy of the Oppressed (Freire, 1972) and Teaching to Transgress (hooks, 1994) core readings. I taught my first college course as an MA student, a developmental English course in the EOPS program, a federal program designed to support lowincome and educationally disadvantaged students. Although we didn't use the word equity, the tacit understanding was that equity was what we were aiming for.

My Master's program helped prepare me for my career, but it was only the beginning of my education as an instructor. I have now been teaching for 14 years as a tenured English instructor at North Coast community college (NCCC) (pseudonym), where I once attended classes myself as a community college student. I have taught developmental courses throughout my tenure at NCCC. In these classes, I found students whose experiences were echoes of my own. Children of immigrants, working students, students whose experiences are often not centered in the classroom setting. Every semester, I would adapt my classes in some way - a new activity, a new reading, a new essay prompt. I committed to constant reflection and adaptation. The students who completed my developmental classes often shared that they felt more confident not only in their academic reading and writing skills, but also in themselves as college students. However, my desire to constantly improve instruction was fueled by the 
students who didn't make it to the end of the semester, students who left my class and the college. I wanted to know what I could do better to support the learning of all the students in my classes, not just those who walked in with better academic preparation. My own understanding of educational inequity - and its counterpart, equity began with the issuing of the first Student Success Scorecard, a tool of the California Community College Chancellor's Office for collecting and accessing student data on a variety of data points. The news that most developmental English students were not making it to college level English, let alone completing academic goals like transferring, getting a certificate, or earning an Associate's degree, was devastating to me as a new instructor. The Scorecard was where I first learned the terminology of "racial inequity" and the important distinction between equality and equity. As I came to understand inequity as disproportionately impacting underserved students, my understanding of equity as the antithesis of inequity began to develop. Equity was not simply a set of data of which to take measure. Striving for equity in my own teaching meant working for the good of those students who hadn't made it. It meant rethinking my practices. It meant changing my thinking and pedagogy to create the circumstances so that all students regardless of the inequity in the prior educational experiences could still be successful. But while I put enormous effort into my own professional learning, sustained systemic change requires far greater commitments to correct the problems of developmental education. 


\section{The Backdrop of Inequity}

Freshman English composition is considered a gatekeeper course because it is presumed to provide students with the critical thinking and writing skills necessary for effective written communication in other college courses. However, in the California Community College system, only half (49\%) of the students placed into developmental English go on to complete a college-level English course (Student Success Scorecard, 2018). After placement in developmental English, students often face long pathways to a college-level English course, which increases the time they must invest in college and the risk they will drop out before reaching their academic goals. In fact, research suggests developmental courses may be the college-equivalent of 'tracking' students, diverting them into a series of courses that ultimately extends the time to achieve their goals, increases costs, and signals to students that they may not be cut out for college (Cuellar Mejia, Rodriguez, Johnson, \& Brooke, 2018; Scott-Clayton \& Rodriguez, 2015). The consistently low rates of persistence and degree attainment for developmental English students illustrate a profound problem of practice in developmental English education.

In English composition studies, developmental coursework has been under heavy scrutiny. Once placed into a remedial pathway, student persistence rates to college-level English and attainment rates of degrees, certificates, or transfer are low, particularly when placed into lower levels of developmental classes (Bailey \& 
Dynarski, 2011; Bailey, Jeong and Cho, 2010; Blumenstyk, 2015; Cuellar Mejia, et al., 2018; Karen \& Dougherty, 2005; Witham, Malcom-Piqueux, Dowd, and Bensimon, 2015). Although research suggests that some students who start developmental English coursework at one-level below transfer ultimately outperform students who start at transfer-level coursework (Southard \& Clay, 2004; Moss, Kelcey, and Showers, 2014), the students who are placed into developmental English coursework at two or more semesters below transfer have significantly lower persistence and attainment rates, especially for female students, students under 25 , and Black students (Xu, 2016). This research suggests that developmental English at one level below college-level can be effective in preparing some students for coursework in college-level English, but longer sequences are detrimental to student success.

Further, the poor efficacy of developmental education nationwide and developmental English specifically is a social justice and equity issue because certain groups of students are disproportionately placed into developmental education, some at lower levels resulting in longer sequences of classes to take, and hence suffer disproportionate impact (Cuellar Mejia, Rodriguez, \& Johnson, 2016). In California, of students who begin in developmental English, only $20 \%$ of Pacific Islander students, $41.1 \%$ of Black students, and $46.7 \%$ of Hispanic students successfully complete the college-level English course, compared to $51.4 \%$ of White students, $57.1 \%$ of Asian students, and $66.7 \%$ of Filipino students (Student Success Scorecard, 2018). These 
disparities in developmental English completion further compound the inequitable conditions in the P-12 system documented by Darling-Hammond (2010) that result in lower levels of college preparation; thus, the students who are the most likely to be placed into developmental courses are also the least likely to succeed in them (Blumenstyk, 2015; Moore, Offenstein, \& Shulock, 2011). These consistently low and inequitable outcomes are a central motive in the push to reform developmental English in California (Cuellar Mejia et al., 2016; Cuellar Mejia et al., 2018; Rodriguez et al., 2016).

Unfortunately, racial inequity also exists in college-level courses. In California, of students who are placed into transfer-level English, $59 \%$ complete the class within the first two years of enrollment. Disaggregating by race shows that African Americans, American Indian, Pacific Islander, and Hispanic students complete transferlevel English at lower rates than their Asian, Filipino, and White counterparts. Specifically, $68.4 \%$ of Filipino students, $67.5 \%$ of White students, and $66.5 \%$ of Asian students complete transfer-level English within two years, compared to only $45.6 \%$ of African American students, $50.7 \%$ of American Indian and Pacific Islander students, and $54.8 \%$ of Hispanic students (Student Success Scorecard, 2018). Although the completion data is better for students of color who enter community college and are immediately placed into transfer-level English compared to data at the developmental level, the inequity between racial groups remains consistent. 
The California state legislature responded to the systemic problem of inequitable outcomes in developmental education with AB705. Passed in January 2018 with an implementation date of Fall 2019, AB705 has two central mandates: reforming placement procedures for incoming community college students and reducing developmental pathways in Math and English. These mandates are structural changes intended to improve equity in outcomes by giving more students access to transfer-level coursework sooner. This legislation resulted in the NCCC English department, like many other English departments in the California community college system, moving to an inclusion model transfer-level course, where students who previously would have been placed at the developmental level will now be able to enroll directly into the transfer-level English course, along with a co-requisite support course intended to provide structured support for those students in coping with the rigors of college composition. $\mathrm{AB} 705$ was the catalyst that sparked contentious discussions in English departments about how to best support underserved students, as AB705 employs a particular discourse of equity (as completion) that may not be consonant with other equity frameworks that faculty may be using. I discuss this legislation and other equity frameworks in more detail in chapter two.

As the research shows, many underserved student populations historically have been placed into a sequence of developmental classes to prepare them for the collegelevel English course (Cuellar Mejia et al., 2016; Moore et al., 2011; Student Success 
Scorecard, 2018; Xu, 2016). Although colleges have increasingly relied on adjunct instructors to teach developmental classes (Bettinger \& Long, 2006; Eagan \& Jaeger, 2009), many developmental English classes have been taught by instructors who were experienced in working with diverse students, and thus presumably had time, education, professional development, and/or experience to develop a diversity-orientation in their instruction that supported these students (Grubb \& Gabriner, 2013). As a result of $\mathrm{AB} 705$, a majority of incoming community college students will now be placed directly into the transfer-level English course. Instructors teaching exclusively at this level or higher may not have had the experience, training, or time to develop an equityorientation in their instruction to support a wide diversity of student background, educational preparation, learning abilities, and skills.

\section{Purpose of the Study and Research Questions}

Instructors and departments are working on how to operationalize equity in light of AB705. Understanding the perspective of developmental English instructors who intentionally attend to equity issues can be a vital resource for instructors of freshman composition. Achieving equity is a collective effort, so how individual instructors conceptualize equity illuminates how English departments are negotiating important issues related to enacting equitable pedagogical practices in teaching composition. More than understanding capacities of individual instructors, we need to learn more about the experiences and perspectives of English instructors who value equity so that 
we can better understand how instructors' thinking about equity shapes their pedagogy and practices within the context of a department where various equity frameworks might be employed.

As California is poised to see a drastic reduction and perhaps even complete elimination of developmental courses, the expertise of developmental English instructors can be a major resource through this transition. Course content, curriculum, and pedagogy fall firmly under faculty purview; hence, instructors are crucial to creating any successful educarional reform (Carrington \& Robinson, 2004). Developmental English instructors who think intentionally about improving their instruction to support diverse students may be successfully manifesting equitable instructional practices particular to the teaching of writing. While research on developmental English has focused largely on outcomes and student experiences, capturing the instructor perspective of supporting equity in the composition classroom is underexamined. This study fills the gap in research by exploring what equity-oriented instruction means to a group of community college developmental English instructors and how the teaching practices they have developed to promote equity in student learning can be resources for college-level English instructors. To this end, the following research questions guide this study: 
1. How do community college developmental writing instructors who selfidentify as valuing educational equity conceptualize equity as it relates to teaching developmental composition?

2. How do these instructors experience and describe their equity-focused practices for teaching developmental composition?

\section{Conclusion}

Research on developmental education shows low success in student access to college level courses, persistence from developmental into college level courses, and completion of academic goals of degree, certificate, or transfer. The California legislature responded by passing $\mathrm{AB} 705$, legislation that reduces developmental pathways and ensures a majority of students will now be placed directly into collegelevel courses in order to improve educational inequity for underserved student populations. Instructors teaching the college-level English course may not have the experience or training in developing an equity-orientation in their instruction that is supportive of the diverse needs and backgrounds of the new inclusion-model collegelevel course. Understanding the perspectives and experiences of developmental English instructors who value equity can illuminate areas of strength in inclusive and equitable teaching practices in the composition classroom.

This dissertation is organized in five chapters. Chapter two presents relevant research on various equity-oriented instructional frameworks and discourses. Chapter 
three details the methodology of the study design, data collection, and data analysis. Chapter four presents the findings from the study. Chapter five discusses implications of the study and offers recommendations for English departments and faculty leaders for supporting faculty through educational reform in their work of promoting equitable outcomes for their students. 


\section{Chapter Two: Literature Review}

The research of this dissertation is coming at a unique moment in time for California community colleges and developmental education. The problematic outcomes of developmental English have been well established and documented, as described in chapter one. Developmental English, however, is not a homogenous, static set of practices. A number of innovative programs, pedagogies, and legislative reforms have evolved out of an intent to improve education for underserved student populations. The most recent of these legislative reforms in California is $\mathrm{AB} 705$, the goal of which is "to ensure that students are not placed into remedial courses that may delay or deter their educational progress" $(\mathrm{AB} 705,2018)$. Because $\mathrm{AB} 705$ is rooted in correcting educational inequity, this legislation provided the impetus for English faculty and departments to deepen their consideration of equity, though $\mathrm{AB} 705$ represents only one framework for understanding equity.

The purpose of the study is to better understand how developmental English instructors conceptualize equity, and how equity-oriented practices and pedagogy play out in college composition classes. Where educational inequity is relatively easy to quantify and measure on specific data points, defining equity is more elusive because it has been invoked in many ways throughout developmental education, particularly as it intersects with teaching composition. Hence, this literature review is intended to examine a variety of equity frameworks that are common in developmental English 
classes. The following strands of equity frameworks are presented in this literature review: AB705 and "the completion agenda"; acceleration; pragmatic practices; learning communities; culturally relevant, culturally responsive, and culturally sustaining pedagogies; and equity-minded instruction. In this literature review, I examine various frameworks of equitable pedagogy, noting points of overlap and points where they stand in contrast. I discuss how each framework might add to instructors' understanding of equitable pedagogy, and I also critique how these frameworks and their corresponding discourses around equity might lead instructors to have "blind spots" that prevent them from seeing key issues.

\section{AB705 and "The Completion Agenda"}

The most prominent equity framework currently influencing developmental education in California is Assembly Bill 705 (AB705), an extension of the SeymourCampbell Student Success Act in 2012. AB705 became law effective in January 2018 with an implementation date of Fall 2019. The Assembly Floor Analysis identified two major reports that contributed to the need for the bill: "Determining College Readiness in California's Community Colleges - A Survey of Assessment and Placement Policies" (Rodriguez, Cuellar Mejia, \& Johnson, 2016) and "Preparing Students for Success in California's Community Colleges" (Cuellar Mejia et al., 2016), both prepared by the Public Policy Institute of California (PPIC). The findings of these reports are consistent with national and state data on developmental education described 
in chapter one. Important findings highlighted from these reports are that a majority of students take at least one remedial course in math, English, or both; that students placed into developmental sequences take approximately two terms to complete the English sequence and 2.5 terms to complete the math sequence - none of which are degreeapplicable. The researchers also found significant inequities, particularly for Black and Latino students and for low-income students; these groups are overrepresented in developmental classes, which means they are disproportionately impacted. Finally, these studies also identified that community colleges had different measures for identifying a student as "college-ready" (being able to enroll in transfer-level coursework), as colleges are able to determine their own methods of assessing college readiness. Although existing legislation had already mandated that colleges use multiple measures for placement, the PPIC studies found that colleges implemented multiple measures in various, inconsistent ways and without the intent to correct inequities. Hence, these reports informed the two central mandates of AB705: a) to reform placement by requiring that multiple measures include the use of high school GPA, which the reports assert is the strongest predictor of student success in college level Math and English, and b) to require that students be able to complete any remediation and the transfer-level, "gatekeeper" Math and English courses in an academic year (AB705, 2018). 
While $\mathrm{AB} 705$ is intended to correct educational inequities, this legislation and its equity framework are problematic for a number of reasons. First, although the PPIC reports focus on racial and economic inequities in access, persistence, and attainment for underrepresented student groups, the equity goals have been overshadowed by the larger fiscal argument that the Chancellor's office has been espousing: to increase "throughput" (completion) by reducing the cost per student through shortening the time to completion. The cost savings of this "completion" agenda is obviously a compelling argument for administrators, legislators, and taxpayers; however, to the faculty who are responsible for the actual implementation, "cost reduction" runs counter to the purpose of education by prioritizing economic interest over student needs. Valuing placement and shortened time to completion as goals loses sight of the specific needs, learning, and lives of the students the bill is intended to support. A second critique of the AB705 equity discourse is that cost reduction by shortening the time to completion means that students have less access over time to curricular and non-curricular supports. With the mandate that the gatekeeper English course be completed within a single year, most developmental pathways will be reduced to a single semester. Students who have been underserved by prior educational experiences will now have only one semester to gain the academic and navigational skills they need to be successful in the gatekeeper course While the accelerated movement in recent years has been working towards this very goal, accelerated courses are not part of the AB705 mandate, nor do all English faculty 
believe acceleration can be successful for all students. A final critique of the AB705 discourse is that the bill presents a structural change to correct systemic inequity that has profound implications on curriculum and instruction, which are under faculty purview, yet $\mathrm{AB} 705$ was developed without the benefit of faculty input. This oversight resulted in the Academic Senate of California Community Colleges passing a resolution in Fall 2018 to censure Chancellor Eloy Oakley for undermining shared governance, most notably in the area of implementing AB705 without input from the Academic Senate. Although the intent of improving racial and economic inequities in education is well-intentioned, this intent has been lost in the problematic implementation and messaging of $\mathrm{AB} 705$.

\section{Acceleration}

One equity framework that holds promise for developmental English is the accelerated movement. "Acceleration" refers to shortening the time students spend becoming "college-ready," or able to pass the college-level, gatekeeper classes in math and English. Accelerated English programs generally fall under two structural models: a co-requisite inclusion model, in which students with lower placement scores are mainstreamed immediately into the college-level gatekeeper course and also enrolled in a co-requisite support class, and a curricular redesign model, which typically includes shortening the developmental pathway by creating a compressed class (two courses taught in a single semester), a single, mega-unit developmental class, or a stretch class 
where the college-level English course is taught over two semesters. Despite structural differences and regardless of discipline, they all follow some basic principles:

- "backwards design" where developmental coursework is designed to meet the expectations for the college-level course

- integrated reading, writing, and critical thinking

- contextualized learning

- affective, non-cognitive supports

- "just-in-time" remediation, where particular basic skills are addressed individually with students based on issues that arise in their work (California Acceleration Project; Hayward \& Willett, 2014).

Accelerated courses also heavily emphasize community building in the class and creating "high challenge, high support" classes (Coleman, 2015).

Because acceleration is intended to improve outcomes over traditional developmental sequences, the focus of most empirical research has been on whether acceleration programs have been successful in achieving their goal of helping students gain college-readiness. Overwhelmingly, the literature shows that accelerated programs are successful in helping students to pass developmental coursework and to complete and pass college-level gatekeeper coursework (Cho, Kopko, Jenkins \& Jaggars, 2012; Coleman, 2015; Hayward \& Willett, 2014; Hodara \& Jaggars, 2014; Jaggars, Hodara, Cho \& Xu, 2015; Jenkins, Speroni, Belfield, Jaggars, \& Edgecombe, 2010). For 
example, in a follow-up study to an earlier 2010 study of the accelerated learning program (ALP) at the Community College of Baltimore County where English acceleration originated, Cho et al. (2012) found that students in the accelerated classes had higher completion and success rates in the college-level English class than students who had enrolled in the traditional developmental pathway. Coleman's (2015) multiphase study examined four colleges in different states and with different models of acceleration; she found not only that pass rates in the college-level course were significantly higher for students who had taken an accelerated class over those who had not, but that they also had higher GPAs in those courses as well. And Hayward \& Willett (2014) found that students who had taken accelerated developmental courses were 1.5 times more likely to complete the college-level course in English, and 4.5 times more likely in math. However, in Hodara \& Jaggars's (2014) study of acceleration and the impact of sequence length on outcomes at CUNY, the researchers found that while students who had taken accelerated classes had increased enrollment in college-level courses, they were less likely to pass than students in the traditional pathway. The researchers explain that while the pass rates fell by $2.5 \%$, the increased enrollment in the college-level course ultimately led to a $2.2 \%$ increase in graduation rates. Despite the Hodara \& Jaggars (2014) finding, the literature overall shows strong evidence that acceleration is helping students to successfully complete college-level gatekeeper courses. 
Due to disproportionate placement of underserved, minoritized students into developmental courses, success in acceleration has had a positive impact on closing the achievement gap. Cho et al. (2012) found that on most measures, Black and low-income students experienced the same effects as White and middle-income students, and they found significant differences between Black and low-income ALP and non-ALP student groups. In Coleman's (2015) comparison of four sample colleges, she found that one college showed significant improvement where the ALP equity gap was 10\% compared to the baseline comparison of $17 \%$. The second college did not have a large enough populations of minority students to make statistical comparisons. The third college showed no statistical change in the gap, and the fourth college showed a complete elimination of the achievement gap in the accelerated course while the comparison group's was 14\%. Even though Coleman's (2015) study found inconsistent results across the four colleges, overall it does suggest that accelerated courses are more effective at closing the racial equity gap than traditional developmental pathways.

Acceleration as a model for developmental English instruction began to take hold in California in 2010 with the establishment of the California Acceleration Project (CAP). Where AB705 is a top-down, legislative mandate that was created without including instructor perspectives, CAP is a faculty-driven initiative to improve inequities in outcomes of developmental education through curricular reform. CAP has 
provided training, education, and professional development for faculty in the principles of acceleration.

Acceleration has many benefits. It provides a model for curricular redesign that is compliant with AB705. Many community colleges in California already had accelerated courses in development or implemented by the time $\mathrm{AB} 705$ was passed. Also, where $\mathrm{AB} 705$ lacked faculty input, $\mathrm{CAP}$ and acceleration is faculty-driven. $\mathrm{AB} 705$ creates the mandates for structural change, but CAP ties directly into researchbased practices and pedagogy for teaching reading and writing, most notably in the cognition-based research on integrating reading and writing (Goen-Salter \& GillotteTropp, 2003; Horning \& Kraemer, 2013; Keller, 2013) and "just-in-time," contextualized remediation for reducing error in student writing (Delpit, 1995; Hartwell, 1985). As an equity framework, acceleration holds a lot of promise for English departments that now have to restructure curriculum to comply with $\mathrm{AB} 705$. There are, however, two important qualities where the equity discourse of acceleration overlaps with that of $\mathrm{AB} 705$ that have yet to be resolved. The first is that $\mathrm{CAP}$ and acceleration utilize a similar discourse as $\mathrm{AB} 705$ where the discourse on equity is focused on outcomes and data on completion. The focus on outcomes and data is not inherently bad; in fact, tracking outcomes is crucial for evaluating efficacy and success of programs. However, not all successes can be measured through data tracking. Student development, critical engagement, self-efficacy, and rhetorical awareness are just a few 
examples of qualities not easily captured by data tracking. A focus on outcomes to the detriment of other markers of student learning is an area of potential problems for acceleration. A second overlap between acceleration and AB705 discourse is in the shortening of time to completion. Other equity discourses that are process-centered require an investment of time. Mentoring, apprenticeship, social community, language acquisition, and even the writing process itself are examples of aspects of college composition that are time-related. Even as acceleration gained more of a foothold in community colleges, a substantial portion of faculty remained skeptical of the shortened timeframe and the ability of this curricular model to meet the needs of all students, especially students who may not respond as well to the intensive pacing of an accelerated class.

\section{Pragmatic Equity-Driven Practices - Universal Design for Learning}

Many teaching practices have been developed and employed to promote equity and support diverse student populations. Universal Design for Learning (UDL) is the quintessential model for a pragmatic approach to achieving equity in instruction. Universal Design originated in architecture to design structures to be accessible for people regardless of any physical disabilities. This same idea has been transposed in education through UDL. Early research asserted that web-based instructional content should be presented and adapted in such a way that it creates access for students of all abilities and not create barriers for students with disabilities (Rose, 2000; Rose and 
Meyer, 2002). These initial ideas have evolved into three central principles of UDL: a) using multiple means of representing information, such as presenting information through images, through web-accessible sites, and through verbal texts; b) allowing for multiple means of expression, where students are allowed a variety of modes for demonstrating their acquisition of material; and c) using multiple means of engaging students in the learning environment (Rose, Harbour, Johnston, Daley, \& Abarbanell, 2006). Examples of UDL practices include utilizing closed captioning on all video content and writing text descriptions of images that can easily be read aloud by voice programs, such as DragonSpeak.

UDL originated as practices to make classroom content accessible to students with physical disabilities, and then it grew to encompass all sorts of learning differences. It has since evolved into a teaching approach that anticipates the pedagogical needs of widely diverse student populations. As an equity framework, UDL conceptualizes obstacles to student success as things that can be overcome through technologies or practices. Instructors adopting UDL are able to meet diverse needs of students through multiple means; however, as a pragmatic approach, UDL presents itself as ideologically neutral, which is a direct counterpoint to other critical approaches to equity that focus on student histories, identities, cultures, and communities. While UDL is a valuable teaching approach that is beneficial to students, $\mathrm{I}$ argue it is incomplete as an equity framework, especially in the lack of attention on racial inequity. 


\section{Culturally Relevant, Culturally Responsive, and Culturally Sustaining Pedagogies}

Just as educational inequity is often associated with systemic oppression, equity is likewise associated with social justice. Cultural relevance is an equity framework that strives for social justice by centering students' cultural lives in education. This framework originated with Culturally Relevant Pedagogy, which challenges teachers to promote the academic success of all students through critical self-awareness, cultural competence, and social critique (Ladson-Billings, 1995). Ladson-Billings argued that Culturally Relevant pedagogy is especially crucial as students of color are taught primarily by white women. This pedagogy combats racial bias and promotes equity through raising teachers' awareness of deficit-based attitudes and focuses instruction on improving their own and their students' cultural knowledge. Gay (2013) expanded on this idea with Culturally Responsive pedagogy. Gay's (2013) approach focuses specifically on the responsibilities and roles of the teacher in creating classroom conditions that engage "the cultural knowledge, prior experiences, frames of reference, and performance styles of ethnically diverse students to make learning encounters more relevant to and effective for them" (p. 31). Paris's (2012) notion of Culturally Sustaining pedagogy takes a slightly different approach, suggesting that instruction should be intentionally designed to respect and preserve students' multicultural, multiliterate selves as an act of resistance against the rising tide of monolingualism and monocultural teaching. 
Culturally relevant, responsive, and sustaining pedagogies evolved from the liberatory ideologies of critical pedagogy (Freire, 1972) and multicultural education (Banks, 2004; Nieto, 1992). Being rooted in multicultural, social justice ideology is a major strength of these pedagogies. Their discourse on equity centers learning around the experiences and lives of culturally and linguistically diverse students. A valuable benefit of this underlying ideology is that it makes these pedagogies particularly aware of and sensitive to racial inequities. Another benefit of these equity frameworks is that they approach students holistically, with a humanistic attention to building students' skills and content knowledge, doing so in ways that empower students towards becoming critical agents of social change. This holistic, humanistic attention can put culturally relevant, responsive, and sustaining pedagogies at odds with other equity discourses that center a shortening of time to completion (like that of AB705 and acceleration) and ideologic neutrality (such as in UDL).

\section{Learning Communities - The Puente Program}

Learning communities (LCs) are a curricular model of instruction that build on the social dimensions of learning. Although LCs can have a lot of variation, this literature review will examine the Puente Program as an example of a successful learning community with an equity-orientation. The Puente Project is a national awardwinning program that has been implemented at high schools, community colleges, and universities across California. At the community college level, the goal of Puente is to 
help students who begin in the developmental English class at one-semester below college-level to reach their goal of transferring to a four-year university. Students move through the program in cohorts that link English classes with counseling classes. Students begin in the developmental English class and then move to the college-level class in the next semester. The Puente model has three pillars: writing, counseling, and mentoring. English faculty who teach in the Puente program are trained in practices that support equity, such as using multicultural literature and "skill-appropriate scaffolding," culturally relevant pedagogy, building relationships with students, and fostering a sense of community (The Puente Project).

Research shows that the Puente Project has been successful in decreasing racial inequity in transfer rates. One report showed that in one year, the transfer rate statewide for "disadvantaged" students was $34 \%$, compared to $44 \%$ for all community college students; the transfer rate for Puente students was 56\% ("Puente Success Data," 2019). One study by Laden (1999) found that the socializing and mentoring aspects helped to improve retention and persistence for the Latino students enrolled in the program. Another qualitative study by Rendón (2002) found that a key feature of the Puente program's structure and content was validation. This validation was seen in how students' felt more positively about their identities as college students and writers, and their ability to be successful and to contribute meaningfully to their communities. 
Puente has proven to be an effective model for equitable instruction. It utilizes culturally relevant pedagogy, so it employs similar discourse around the transformative and liberatory potential of education, and the holistic, humanistic enterprise of attending to all aspects of student development, not just knowledge/skill building. Puente was established over 30 years ago at Chabot College, and since then has been adopted at 65 community colleges in California, but it exists as a small-scale program, usually offering two or three sections on a college campus. The program requires investment from college administrators for Puente faculty to attend the required trainings and conferences by providing necessary reassigned/release time and other financial support. It also requires substantial time commitment for instructors beyond the normal classroom teaching for field trips to visit university campuses, for personal support to students, for community-building and cultural events, and for training. The focus of Puente specifically on transferring also precludes other academic goals that students may have, such as earning an Associate's degree or a certificate. Puente is a strong model for successful learning communities in equity-oriented instruction, but it would require adaptation for departments to bring it to the scale needed to meet $\mathrm{AB} 705$ mandates.

\section{Equity-mindedness in Instruction}

The equity frameworks addressed in this literature review focus predominantly on practices, programs, and structures that are being employed to improve equity in 
education. Bensimon and Harris's (2012) theory of "equity-mindedness" is a departure from these in that it focuses on educator conceptualizations, or how they think, about equity. America's Unmet Promise: The Imperative for Equity in Higher Education (Witham et al., 2015) argues that any reform in higher education must begin with an awareness of the ways many groups have been excluded from educational opportunities or marginalized in educational institutions. They assert that, in order to address this systemic exclusion that has led to poor academic outcomes, educational leaders, institutions, and teachers must adopt an equity-oriented mindset for rethinking their policies and practices. Bensimon, Dowd, and Witham (2016) explain that educators coming from a traditional mindset about student success would consider what skills or knowledge are students deficient in and how should they be remediated, whereas equity-minded educators would ask, "Why are our practices failing to produce success for our students of color?" Equity-minded educators see disproportionate academic outcomes as the result of problems within the educational system; this view stands in sharp contrast to the deficit-minded perspective (Valencia, 1998), which assumes any negative outcomes are the result of some characteristic or quality of the student. Equitymindedness also locates the responsibility for outcomes with the institution and educators. As such, it also assumes that effecting change is within the educators' locus of control. 
Although Witham et al. (2015) focus primarily on implementing equitymindedness at the institutional level, it is also pertinent at the class level. Bensimon et al. (2016) insist that instructors must actively learn and practice equity-mindedness to truly provide education for all students and to dismantle systemic racism in education. Equity-minded instruction is rooted in critical pedagogy that seeks to disrupt the systems that have historically excluded certain groups from educational opportunities (Bensimon, 2007; Bensimon \& Harris, 2012; Majors and Ansari, 2006). Majors and Ansari's (2006) study of an urban university's teacher education program examined pre-service teachers' emerging understandings of literacy and how well those teachers were able to adopt a critical stance towards literacy and education. Majors and Ansari (2006) assert that, without an explicit equity-minded agenda, the program and the preservice teachers it was producing lacked critical reflection, resulting in a "one size fits all" teaching approach. They argue for teacher education programs to adopt equity frameworks to be race-conscious and equity driven, and to disrupt the inherent disparities in colorblind teaching approaches. In sum, this research on equity suggests that equity-minded instruction needs to be purposefully developed in faculty by engaging in critical reflection in order to change faculty beliefs about student ability and the faculty's role in improving outcomes for student populations who are worthy of attention. Although equity-mindedness is limited in that it does not provide specific guidance on employing equity within academic disciplines, like English composition, 
the benefit of this theory is that it can act in complement with the other equity frameworks presented in this literature review.

\section{Conclusion}

The purpose of this study is to better understand how English instructors who value equity conceptualize and operationalize equity in their developmental classes. The literature included in this review demonstrates that there are widely varying notions of what constitutes equitable pedagogy and practice. These studies also demonstrate that instructors and departments have an array of tools at their disposal for enacting equity both within the classroom and structurally through curriculum. Despite the variation in approaches to equity across the literature, the research presented here suggests that these practices and pedagogies have benefits for all students' learning, but especially for students of color and other underserved students who have experienced inequity in education. Intentionally attending to equity can improve equitable outcomes.

What is missing in the literature is the embeddedness of equity within composition pedagogy. There is a gap in the literature where writing pedagogy intersects with the social factors and intersubjective dimensions of learning and instruction. The intersubjectivity of instructors' everyday experiences form the basis not only for student learning, but also for providing the optimal conditions under which equity can be employed. The study of this dissertation seeks to fill this gap by 
illuminating the thinking and practices of writing instructors who value equity. Chapter three will outline the methodology and design of this research. 


\section{Chapter Three: Methodology \\ Overview}

The teaching and learning environment of the developmental English classroom is shaped by each teacher's instructional practices, pedagogy, curriculum, and views of both student and teacher roles. However, there is a dearth of research that focuses on the experiences and perspectives of teachers of developmental writing, particularly those who identify as equity-oriented. Educators who are equity-oriented are interested in dismantling inequity through their classroom practices (Bensimon, 2007; Bensimon et al., 2016; Bensimon \& Harris, 2012; Witham et.al, 2015). The purpose of this study is to better understand how instructors perceive equity and its role in the teaching of writing, and to learn what equity-driven practices could look like in a composition classroom. To explore these topics, this study is guided by two research questions:

1. How do community college developmental writing instructors who selfidentify as valuing educational equity conceptualize equity as it relates to teaching developmental composition?

2. How do these instructors experience and describe their equity-focused practices for teaching developmental composition?

Qualitative research is fitting for this study because it allows for capturing and examining individuals' perspectives of their everyday experiences in relation to their social worlds (Denzin \& Lincoln, 2013). This study examines the perceptions, 
practices, and experiences of community college developmental writing instructors. Capturing these experiences can enhance understanding of what is useful, necessary, or detrimental in achieving equitable outcomes in college composition classrooms. This chapter details the methods and procedures for the study, as well as their rationale.

\section{Methodology}

\section{Research Design}

Denzin and Lincoln (2013) assert that qualitative researchers are "committed to an emic, ideographic, case-based position, which directs their attention to the specifics of particular cases" (p.19). Hence, this study employs an embedded case study design to explore the perspectives and experiences of developmental writing instructors in the community college. Yin (2018) defines case study as a research methodology that is best suited for 'investigating a contemporary phenomenon (the 'case') in depth and within its real-world context" (p.15). In this study, the single case is the English department at North Coast Community College (NCCC), which for the past two years has been preparing for the implementation of $\mathrm{AB} 705$ mandates, the context for the case. The participant instructors are at the heart of the study and serve as multiple focal points for comparison embedded with the particular context of the case (Yin, 2018).

\section{The Case: The NCCC English Department}

Setting. The study took place at NCCC, the community college where I am employed as a full-time, tenured English instructor. NCCC is located in a large 
suburban city north of the San Francisco Bay Area. With approximately 19,000 FTES, NCCC is a mid-size campus serving a predominantly White student demographic (50\%). However, four years ago, NCCC earned designation as a Hispanic Serving Institution with $33 \%$ of the student population identifying as Latinx.

At NCCC, college-level composition and developmental reading and writing are under the purview of the English department. NCCC has 26 full-time, tenure track instructors and about 60 part-time, adjunct instructors. Although $\mathrm{AB} 705$ will change both placement procedures and curriculum, at the time of this research, the traditional developmental pathway was comprised of three courses before the transfer-level freshman composition course. In addition, a separate department, College Skills, also offered a basic-skills writing course for students at the lowest end of the placement testing range. Students were placed into a course level based upon results of the college-administered placement test, which included a writing sample. Thus, a student with a score at the lowest end of the placement test would need to complete a full two years of remedial courses (one course in College Skills and three courses in English) before being eligible to take the transfer-level composition course.

Preparing to meet the requirements of $\mathrm{AB} 705$ has been a daunting task in the short timeframe from the passing of the legislation in January 2018 to implementation in August 2019. The college met the AB705 mandate to improve placement procedures by implementing a guided self-placement tool, recommending placement to students but 
allowing them the freedom to choose their entry level course in English and Math. As the college was in the process of developing guided self-placement, the English department was considering curricular redesign of the pathway. After considering various curricular models, the department ultimately decided to eliminate the two lowest-level developmental classes and to keep the accelerated and traditional developmental classes that are one-level below transfer-level. In addition, the department chose to adopt an inclusion model college-level class with a co-requisite support course ${ }^{1}$. At NC, under the new inclusion model set to begin in Fall 2019, students who historically would have been placed into lower-level developmental courses based on their placement score will now be able to choose to enter a pretransfer level developmental class or to directly enter the college-level course, with their enrollment linked to enrollment in a co-requisite course designed to provide additional support and instruction.

The Context. Over time, faculty in the NC English department have pursued a variety of teaching methods and programs that reflect the equity frameworks discussed in chapter two. For example, the learning communities (LC) program was active for several years before the most current iterations of LCs evolved, which are tied to grantfunded initiatives, such as the LC to support Latinx students as part of the HSI grant, or the LC supporting Asian and Pacific islander students financed by Student Equity

\footnotetext{
${ }^{1}$ The co-requisite inclusion model was the original model of acceleration, developed by the Community College of Baltimore County in 2007.
} 
funds. Puente is another LC model that has been successful for over twenty years on campus. In the mid 2000's, as national and state research on the questionable efficacy of developmental education was being widely disseminated and the equity framework of completion and outcomes took greater hold in community colleges, the NC English department developed a number of strategies to improve outcomes in our developmental pathway. These supports included requiring conferences with faculty and staff tutors at the Writing Center, professional development and training in Reading Apprenticeship, and supplemental instruction provided through an embedded peer tutoring model. The department's Developmental Committee also took on the task of piloting new course curriculum. For example, in the mid 2000's, a group of English instructors developed and piloted compressed classes. In an effort to shorten the pathway, a single, seven-unit mega-course was created that combined the objectives and outcomes of two of the three developmental courses so that students could earn credit for both classes in a single semester. The compression model was later replaced with the accelerated model. A small but growing group of instructors were trained through the California Acceleration Project in the principles of acceleration, developed the course curriculum, and then piloted our first accelerated course. While the department overall supported implementing our accelerated course as part of our regular course offerings, a large contingency of the English faculty was also insistent that the traditional three-course developmental sequence be maintained. 
While instituting any program that is radically different from the norm will draw skeptics and criticism, the debate in our department took an unexpected turn as the discussion shifted from a critical questioning of the accelerated pedagogy and curriculum into a much deeper philosophical argument against a neo-liberal project to industrialize education, which heralds acceleration as the pinnacle of efficient, factory schooling (Field notes, Spring 2018). Several faculty from English and other departments as well had taken issue with the arguments of Redesigning America's Community College (Bailey, Jaggars, \& Jenkins, 2015) and its argument to revise the community college system through the framework of the completion agenda. Redesigning presents research on poor outcomes of developmental education, the achievement gap and equity gap, how underserved student populations, like first generation college go-ers and students of color, are disproportionately impacted, and how this educational problem is a financial crisis for states, institutions, and students. Redesigning argues for guided pathways, more clearly outlined plans for goal-setting and completion, and higher and faster graduation rates. Faculty leaders at NCCC, several of whom are English faculty, argued vociferously that state legislatures or college administrations imposing structural and curricular reforms was ill-founded, deprofessionalizing to faculty, and a violation of the faculty's purview over curriculum design. Finally, they argued that financial arguments are tantamount to colleges becoming efficiency models of education that are abhorrent to the true goal of higher 
education: to produce enlightened and knowledgeable citizens, not to produce a labor force that commodifies humans as working capital. Skeptics of AB705 argue that this legislation promotes an efficiency model of education rather than a model that emphasizes intellectual growth. NCCC English faculty are teaching embedded within the larger context of a department, which in turn is operating within the context of the CC system and state legislation.

\section{Role of Researcher}

I have taught full time as a tenured English instructor at NCCC for the past thirteen years. At the time I was hired, I was a recent graduate with a Master's in English with a concentration in Rhetoric and the Teaching of English, with specific training in liberatory, critical pedagogy, such as that established by Paulo Freire (1972) and bell hooks (1994). As a compositionist, I actively sought to teach developmental classes where students who had been consistently excluded from educational opportunities typically were placed.

All of the participants in the study are colleagues with whom I work in a professional capacity. Because participants know me through my role and identity as a colleague and English instructor, I began the initial interviews by reviewing my study and describing my role as a graduate educational researcher. An unexpected strength from my role as a qualitative research was my position as an insider and veteran instructor in the department. The insider can be a difficult position because of the 
potential influence she may have on participant responses, and Charmaz (2014) warns researchers to maintain neutral distance, as even non-verbal cues may telegraph encouragement or dismay. The unanticipated benefit was the trust and rapport that already existed between researcher and colleagues, allowing for richer conversations and deeper critical reflection of the participants.

\section{Population and Sampling}

Recruitment. Because this study was conducted at the campus where I work, convenience sampling was used. Recruitment occurred from August through midOctober 2018. Invitational recruitment letters were sent to all instructors at North Coast Community College (NCCC) (pseudonym) who had taught any developmental level courses in the prior two years. Initial recruitment yielded six participants, the ideal number for this study. Six viewpoints provided ample data for identifying patterns while ensuring variety in viewpoints. Scheduling conflicts arose for two of the instructors, resulting in a loss of those participants. As a result, an additional round of invitations was sent out, yielding two more participants for a final total of six participants.

Selection criteria. Because this study aimed to understand how instructors conceptualize equity, the recruitment letter sought instructors who self-identify "equity in education as a personal professional value" (Appendix A). Ideal participants also needed to have at least two years of experience teaching English at the developmental 
level to ensure that data was responsive to thinking about equity, not to be confused with challenges that arise when teaching new material or teaching for the first time. A final criterion was that participants needed to have taught at NCCC for at least two years so that they had enough experience to reflect on the context and its influence on their teaching. A preferred criterion was that participants currently be teaching a developmental course or have taught in the semester prior so that they could have access to current, updated course materials and so that their thinking about course materials would be fresh. All participants met the selection criteria and the preferred criterion.

To improve transferability of findings, an attempt was made to select participants with demographic diversity (at least $33 \%$ variation, or $1 / 3$ of participants), including diversity in years of teaching experience, fulltime/adjunct status, gender diversity, and ethnic diversity. This diversity was achieved on all points except for fulltime/adjunct status, where only one adjunct instructor was recruited.

Table 1. Demographic information of participants.

\begin{tabular}{l|cclll} 
& $\begin{array}{l}\text { How long } \\
\text { have you } \\
\text { taught } \\
\text { developmental } \\
\text { English? }\end{array}$ & $\begin{array}{l}\text { How many years } \\
\text { have you taught at } \\
\text { the postsecondary } \\
\text { level? }\end{array}$ & $\begin{array}{l}\text { What is your } \\
\text { employment } \\
\text { status? }\end{array}$ & $\begin{array}{l}\text { Please } \\
\text { describe your } \\
\text { race/ ethnicity }\end{array}$ & $\begin{array}{l}\text { Please identify } \\
\text { your gender }\end{array}$ \\
\hline Amy & 18 & 18 & Full-time & Asian & Female \\
Jack & $\mathbf{8}$ & $\mathbf{8}$ & Full-time & White & Cis male \\
Judith & 10 & 10 & Full-time & White & Nonbinary \\
Leny & 5 & 5 & Full-time & Mexican & Female \\
Rosina & 2 & 8 & Part-time & White & Female \\
Scott & unknown & 23 & Full-time & White & Male
\end{tabular}




\section{Participant Profiles}

Amy. Amy holds an MA in English with a concentration in Composition and a minor in ESL, so she has had specific education in composition theory and pedagogy. She described herself as coming from a Dutch Indonesian family that was largely conservative. Her early education was a haven for her: "School was such a beautiful place for me. My teachers loved me, and I loved them" (Amy, interview, 2/11/19). She feels her identity as an Asian woman in her early 50's is a benefit to her teaching because it reduces threat. She explained that students “...would either see me... as their mom or as their grandmother. And whatever roles they had with that woman. So then it was great. Right? Because I'm no threat. And the other thing is, too, whatever biases or preconceived ideas they have about Asians, that also played in my favor" (Amy, interview, 2/11/19).

Amy has taught at NCCC for the past six years, though her teaching career spans nearly two decades. Amy described that her primary teaching assignments are usually developmental courses, by her choice, although she has not taught the accelerated course because she "never believed in acceleration" (Amy, interview, 10/12/18). She considers developmental English to be some of the most important work of the community college (Amy, interview, 10/12/18). For Amy, teaching is not a job, but a calling. She described, "I spent all of my life [teaching], this is what I love. I'm not an activist, and Im not Amnesty Intemational, but this is my life" (Amy, interview, 
10/12/18) [emphasis in original]. She has also held several official positions in the faculty union, and she participates actively in department committee and curriculum work (Field notes).

Jack. Jack holds a Master's degree in English, with special coursework in composition theory and developmental composition. Like Amy, he consistently elects to teach developmental classes, including the accelerated course, because he loves the work. He began his work at NCCC as an adjunct instructor before being hired into a full-time, tenure track position. Although he is a relatively young member of the department in his 30 's, he has been a leader in department work. As the department has prepared for implementing $\mathrm{AB} 705$, Jack has represented the college at state meetings about implementation. With his experience, he led the faculty workgroup that developed the course outline and curriculum for the new co-requisite course for students in the college-level English course whose placement indicates a need for additional structured support. He is also leading a Community of Practice group for English faculty teaching the support course.

Although Jack described himself as White, cis-male, from a privileged educational background, he also described himself as a "high-anxiety student... who threw up before school every day for a decade" (Jack, interview, 10/18/18). Though he had access in high school to a high-quality program with hands-on, problem-solving curriculum, he also saw the injustice that all students didn't have access to the same 
program, especially when the mainstream curriculum was "boring." These early educational experiences shaped Jack's teaching philosophy that learning can and should be challenging and engaging. Those experiences also sharpened his awareness of how traumatic educational experiences inhibit learning.

Judith. Judith has been teaching English composition at the college and developmental levels for the past 10 years. She holds a Doctorate in Educational Leadership and a Master's in Composition theory. Like Jack, Judith is a relatively young faculty member in her 30's, yet she has been an active leader in supporting curricular reform of the developmental pathway. As one of the original instructors in the department trained by the California Acceleration Project, Judith helped develop the department's accelerated class. She has also taught for several years in a learning community that is funded through the HSI grant awarded to the college to support the growing Latinx population, and she teaches classes to incarcerated students in partnership with the local jail.

Although she was raised in a conservative, White, middle-class family in Southern California, her privilege was tempered by her intersectional identity as a queer lesbian. Judith described her experience of attending a large, racially diverse urban high school where she witnessed daily racism and discrimination by the school against students of color: "The same time as I knew that I could enjoy white privilege next to all of the black girls on my basketball team, I also was super paranoid about being in the 
closet. I had this checklist of things - maintaining appropriate femininity, which is different than being in the closet about being a lesbian...I think I always have just been hyper aware of all of those differences, in particular how they played out in education spaces" (Judith, interview, 12/19/18). These early experiences crafted her core value of social justice which informs her teaching philosophy, pedagogy, and practices.

Leny. With six years of teaching experience, Leny is one of the newest members of the English faculty. She holds an MA in English and has completed coursework for a Ph.D. in Literature. Part of her coursework included a pedagogy course in teaching composition, and she was mentored in teaching composition for three years as a graduate student. Despite her recency in joining the department, Leny is an active participant in the work and culture of the department. She has coordinated faculty readings, sits on various committees, and has taught the accelerated class and in the HSI-funded learning community.

Like the other participants, Leny is personally invested in teaching developmental courses. She described traumatic experiences in her own education taking developmental classes in high school that "felt stupid and demeaning" (Leny, interview, 12/4/18). She explained that, "in high school, I had friends who were all college bound because we moved from Gilroy, which was predominantly Mexican, to South San Jose, which is predominantly White. And so I found myself at high school with all these middle-class, college bound students, and it was very painful because I 
didn't have their upbringing, so I was doing poorly in classes" (Leny, interview, 12/4/18). These early experiences in education convinced her that college was not for her. She finally enrolled in NCCC as an older adult student, taking English classes from instructors who are now her colleagues today. Leny empathizes and identifies with many of the students in her developmental classes, who have also been underserved by previous educational systems.

Rosina. Rosina is the lone adjunct instructor participant in this study. She holds a Ph.D. in Linguistics and has taken graduate level coursework in composition theory, basic writing, and assessment. Although she has been teaching for over eight years, only the last two have been at the developmental level. Her interest in teaching composition grew out of her early teaching at a university. She described the university, "I think the acceptance rate they have is like $87 \%$ or something... It was really diverse, and that's what got me interested in studying composition because I wasn't teaching writing there. I was teaching linguistics... and I got these stacks of papers... and I was like, 'What am I going to do with this, because some of these are a mess and I don't know what to do. How am I dealing with this?'” (Rosina, interview, $12 / 19 / 18$ ). With a background in linguistics, Rosina is particularly interested in the power of language, a philosophy she brings to her developmental classes.

Scott. With over 20 years of teaching experience, Scott is the veteran instructor among the participants, and he holds a Ph.D. in American Literature. He is a newly 
tenured member of the NC English department, and he has experience teaching at both universities and community colleges. Although he did not identify a specific number of years that he has been teaching developmental courses, he said he began teaching developmental classes when he started working at community colleges. Since joining NCCC, he has devoted much of his professional development to learning more about supporting diverse learners. He is an active member of the faculty, serving on department committees and holding positions in the union. Scott has been a part of a critical team of instructors who designed the new Guided Self-Placement tool for the college to fulfill the AB705 mandate on reforming placement protocols.

\section{Statement of Ethical Considerations}

There were three potential risks associated with this study. One potential risk was faculty experiencing uncomfortable emotions when being asked about their teaching practices, perspectives, and experiences. This risk was minimized by offering breaks and allowing the faculty to stop at any time. One participant did experience strong feelings and twice had overwhelming emotional moments; however, she chose in both instances to continue the interviews. Another potential risk was loss of privacy. This risk was minimized by conducting interviews in private locations out of hearing range of others. In addition, all course documents and interview transcripts have been kept in a locked, secure cabinet in the researcher's exclusive possession. 
The third risk is a potential loss of confidentiality if security of data (interview transcripts, course documents, field notebook, data memos) were compromised. Confidentiality of the data has been protected by using pseudonyms for participants and redacting names off hard copies of any data. Participants were offered to choose their own pseudonyms but declined, so pseudonyms have been chosen by the researcher ${ }^{2}$. Pseudonyms were used on all digital copies of transcripts, documents, data memos, and research reports, and on hard copies of documents, including the researcher's field notebook. Digital copies of all research data are stored in a device with full disk encryption and password-protection. This device and any hard copies of documents provided by participants and the field notebook are also in a locked data archive box. All data are kept in the researcher's secured office in a locked cabinet. Only the researcher has access to the data.

\section{Data Collection Procedures}

During recruitment, instructors were asked to commit to two 60-90 minute interviews and to provide course documents, including course syllabi, essay prompts, reading lists, and grading rubrics. Once instructors had agreed to the commitments and informed consent had been obtained, participants were then emailed a pre-interview questionnaire for basic background and demographic information. Included in this email was a request for the course documents. Although it was suggested that course

\footnotetext{
${ }^{2}$ Five of the six pseudonyms were chosen for literary scholars and theorists: Judith Butler, Jack Halberstam, Rosina Lippi-Green, Leny Strobel, and Amy Tan. The final pseudonym was chosen for my mentor during my Master's program who profoundly shaped the trajectory of my career, Scott Miller.
} 
documents be submitted by the first interview, participants submitted these documents at their convenience.

Initial interviews took place from mid-October through December 2018. Second interviews took place from December 2018 through February 2019. These semistructured interviews lasted 60-90 minutes each. All interviews were audio-recorded and professionally transcribed. Each transcript was then reviewed for accuracy and consistency with the audio recording.

I developed interview protocols for both interviews. Questions for the interview protocols were intended to assess how instructors conceptualized equity and how equity-related teaching might play out in their developmental English classes, particularly in light of the various equity frameworks presented in the literature review. The domains of interest in the first interview protocols are: instructor definitions of equity, the role of equity in teaching developmental English, and specific practices the participant has developed that they perceive as promoting equity in instruction (Appendix B). After coding the acquired data corpus after the initial interview, I developed questions for the second interview to explore more deeply the domains of composition instruction raised in the first interview and to corroborate responses from the first interview; thus the second interviews served as a separate data point (Yin, 2018). Second interview protocols also explored the course documents that had been provided by the participants. Although second interview protocols were developed 
separately for each participant based on their first interview data and course documents, there was some consistency in questions across participants (Appendix C). Included in both protocols are a warm-up question to set the tone and establish rapport, and a wrapup question to provide closure to the interview and end on a positive note. Validity of the interview protocols is high because the questions in the protocols ask instructors to describe their experiences and perceptions of equity in teaching developmental English, topics which are directly related to the research questions. Reliability is mostly strong because participants all have a common teaching experience and common teaching context, but it is somewhat reduced due to unknown variability in participants' professional learning and prior knowledge of research on developmental education and educational inequity.

\section{Data Analysis Procedures}

Case study methodology calls for "consolidating, reducing, and interpreting what people have said and what the researcher has seen and read" (Merriam, 1998, p. 178). To consolidate and reduce data, I used a "ground up" approach to code data, aggregate codes for patterns, and generate broad categories for more detailed analysis (Charmaz, 2014; Yin, 2018). These categories were analyzed using constant comparative methodology, which allows for repeated rounds of analysis for data to be coded and categorized for themes (Charmaz, 2014; Merriam, 1998). Data sources identified for this study are interview transcripts (two interviews per participant), course 
documents (syllabus, sample essay prompts and corresponding grading rubrics), and researcher field notes.

Because this research focused on participant perceptions and experiences, I utilized predominantly process, values, and in vivo coding, and, periodically, emotion coding when appropriate (Miles, Huberman, \& Saldaña, 2014). After completing most of the first interviews and collecting most of the course documents, I performed first cycle coding on approximately 250 pages of data, which yielded 26 pages of codes. (All pages in data collection and coding are single-spaced.) These codes were then analyzed for patterns and consistency in addressing the research questions, yielding 15 broad categories. I drew from these categories to partially create questions for the second interviews. After all data collection was complete, I then performed second cycle coding on the full data corpus of 402 pages. Second cycle coding yielded an additional 16 pages of codes. First and second cycle coding of over 400 pages of data yielded a total of 42 pages of codes. Using constant comparative methodology, I deduced these codes into 15 broad categories. These categories coalesced into three broad themes that related directly to the research questions and became the findings of the study.

Field notes of observations of the department helped shape understanding of the context. Data memos were also used throughout data collection and analysis. Data memos are analytical tools to help examine more closely what is going on in a particular data excerpt; these focused analyses are the bridge between data, codes, and 
categories (Charmaz, 2014). Both field notes and data memos were coded and compared to codes from participant data sources to ensure consistency of interpretation. For reliability, emergent themes and categories were shared with critical colleagues at multiple points throughout the process.

\section{Validity}

To improve validity and reliability of this case study, I triangulated by collecting multiple sources of data (Merriam, 1998), specifically two interviews from each participant, a variety of course documents, and field notes. Because the second interviews incorporated questions to corroborate statements from the first interviews, they serve as a separate data point for triangulation (Yin, 2018). These two interviews and course documents allow for triangulation of data by providing direct evidence of how instructors conceptualize equity and how that conception is reflected in their pedagogy as well as in written communications to students. Field notes and data memos provided critical context for interpreting the data. 


\section{Chapter Four: Findings \\ Overview}

As English departments throughout California were preparing for the Fall 2019 implementation of $\mathrm{AB} 705$, resulting in sweeping changes in their developmental pathways, I sought in this study to answer the questions: How do community college developmental writing instructors who self-identify as valuing educational equity conceptualize equity-focused pedagogy? How do those instructors describe their equityfocused practices for teaching composition? To answer these questions, I conducted two interviews each with six participants and collected instructor-created course materials, including syllabi, essay prompts, assignment sheets, and grading rubrics between September 2018 and February 2019. These interviews provided insight into developmental instructors' experiences and perceptions of educational equity and its role in teaching composition. The material artifacts provided evidence of how those perceptions were translated into direct communications with students. Using a grounded theory approach with constant comparative methodology (Charmaz, 2014; Merriam, 1998; Yin, 2018), several themes emerged from the data analysis. I identified themes for their applicability in addressing the research questions, for their revelatory impact on participants' data, and for their patterning across most or all of the participants' data. These themes formed the basis of the findings. 
This study yielded three major findings. The first and most prominent finding is that participants conceptualized equity-oriented pedagogy in terms of student empowerment. Participants operationalized this concept of 'equity as empowerment' in four main ways: 1) enacting culturally relevant pedagogy; 2) humanizing feedback through in-person writing conferences; 3) building relationship-centered classes; and 4) co-constructing the class with students. The second finding of this study is that participants perceived equity-oriented pedagogy as being enmeshed with - and often in opposition to - departmental discussions of rigor. Participants offered three main critiques of connotative associations of rigor, where rigor was associated: 1) with being rigid; 2) with achieving correctness in "standard English;" and 3) with suffering. The third finding is that participants described the integration of equity-oriented pedagogy within the context of the department as being contentious. Participants identified three specific tension-points: 1) mixed feelings about the potential of $\mathrm{AB} 705$ to effect positive, equitable change; 2) the necessity of addressing racial inequity; and 3) inconsistency in defining equity. A fourth point identified by participants was not a point of contention, but rather a way of resolving these and other points of contention; participants identified critical self-reflection as a crucial factor in departmental considerations of how to integrate equity-oriented pedagogy. The findings of this study reveal that meaningfully promoting equity-oriented practices requires acknowledgment of how equity plays out both in classroom instruction and in departmental discourse. 
Table 2: Summary of findings

Finding \#1: Participants conceptualized equity-oriented pedagogy in terms of student empowerment

'Equity as empowerment' was operationalized in four ways:

1) enacting culturally relevant pedagogy

2) humanizing feedback through in-person writing conferences

3) building relationship-centered classes (spotlight on Leny)

4) co-constructing the class with students (spotlight on Judith)

Finding \#2: Participants perceived equity-oriented pedagogy as being enmeshed with - and often in opposition to - departmental discussions of rigor

Critiques offered of three main connotations of rigor:

1) rigor associated with being rigid

2) rigor associated with achieving correctness in "standard English" (spotlight on

Rosina)

3) rigor associated with suffering (spotlight on Jack)

Finding \#3: Participants described the integration of equity-oriented pedagogy within the context of the department as being contentious

Contention centered around three specific tension-points:

1) mixed feelings about the potential of $A B 705$ to effect positive equitable change

2) the necessity of addressing racial inequity

3) inconsistency in defining equity (spotlight on Amy)

4) Participants also identified critical self-reflection as a crucial factor to resolve points of contention

These findings are presented first with an overview and explanation of each

finding, and then using participant voices to illustrate and develop the critical elements

of each finding outlined above. To honor the experiences of each participant as an

embedded case within this study, I have included participant "spotlights" with

biographical sketches for added texture in capturing how an individual participant's

experience highlights a particular point within a finding. 
Pseudonyms are used for the institution, for all participants, and for any students or other instructors mentioned in interview excerpts.

\section{Findings}

\section{Equity as Empowerment}

The inherent philosophy behind any English class, but particularly a developmental English class, is really equity.... When you can write, you're empowered. When you can read, you are empowered. These are tools to navigate the world, and these are tools that are used to manipulate us all the time. And for a student, they develop this confidence that's so massively important. (Jack, Interview, 10/18/18)

The first and most important finding in this study is that participants conceptualized equity-oriented pedagogy in terms of student empowerment. Almost all of the participants in this study described the empowerment of students as central to their thinking about equity. Critical theories of pedagogy and education identify the empowering of students to be agents in their own lives, educations, and communities as a goal of education (Freire, 1972; hooks, 1994; Ladson-Billings, 1995; Paris, 2012; Rendón, 1994; Rendón, 2014). Keying in to the discourse of critical pedagogies, many of the participants in this study defined the purpose of college composition as providing students with the fundamental tools of empowerment. Leny stated, "If I had to put it as succinctly as possible, this is the reason that I'm teaching. It's to empower students," 
(Leny, interview 2/4/19). In addition, the opening epigraph for this theme illustrates Jack's connection between equity and the reading, writing, and critical thinking that broadly comprise the content of composition courses. Rather than think of the purpose of developmental English in the traditional sense of remediating students who are deficient in skills, Jack and four of the other participants in this study identified the purpose of developmental English and academic literacy as the tools for people to think critically about culture and the systems that govern their lives.

All of the participants described a variety of pedagogical practices they felt promoted equity by supporting empowerment of all students. Participants operationalized the concept of 'equity as empowerment' in four main ways: 1) enacting culturally relevant pedagogy; 2) humanizing feedback through in-person writing conferences; 3) building relationship-centered classes; and 4) co-constructing the class with students.

Enacting culturally relevant pedagogy. Several of the participants described their teaching in ways that illustrated the qualities of culturally relevant pedagogy, although they did not use the term specifically. Ladson-Billings (1995) describes culturally relevant pedagogy as teaching that attends to students' identities in all aspects of learning. She explains that this pedagogy empowers students by setting high academic expectations, creating curriculum that is relevant and relatable to students' lives, and cultivating critical consciousness in students that enables them to effect 
change in their own lives and in their communities. Four of the participants in this study talked about activities and assignments that illustrated some of the defining qualities of this pedagogy. In one salient example of a text she was using in a lower level developmental class, Leny explained:

We're reading... an anthology of essays about happiness, and they're hard. They're, like, studies of positive psychology, and it's theory, and it's philosophy. It's not easy stuff to read. And I just started them a couple of weeks ago... and they've just become so excited because the content is about happiness. And we're talking about, "Well, what makes it happen? What makes you happy? And what things sound like they'll make you happy, but actually the long-term effects of it make you unhappy?" And so, just in discussing these studies, they're having those light bulbs go off, and it's making them more engaged, and they're leaving class laughing. (Leny, interview, 12/4/18) Although Leny described these studies as "hard," the students were thoughtfully engaging with the material because the discussions focused on connecting the content to students' lives. Students can easily generate responses to the question of "What makes you happy?" The readings Leny assigned on theory and philosophy related to happiness, however, allowed students to engage in critical thinking by problematizing what seemed like a simple topic. The more critical question, "what things sound like they'll make you happy, but actually the long-term effects of it make you unhappy?", 
invites students to deepen the complexity of their thinking through personal, critical reflection, which Leny felt bolstered student engagement.

Jack also provided several examples of using pop culture references to scaffold discussions of more academic topics. In one example, he described how emojis led to a discussion of linguistic privilege and audience:

For example, a few weeks ago, I did an activity where I brought in a bunch of emojis and I projected them on the screen. And I have my students talk me through...all the emojis with the hearts. So, the blowy one, the kissy, the eye and hearts, the different colors of hearts, the swirly hearts. And we had about a 3-minute conversation about the rules of when you use certain emojis. And it was like, "So when is it appropriate to use this? Like, what date do I use this one?... Oh, this is one that you send to, like, grandma... and then you can't send too many of these in a row because then you come off as crazy." [It was] a really thoughtful conversation. And then I gave them James Baldwin's, "If Black English isn't a Language Then Tell Me What Is?" And we just had this full conversation about privileged language. Like, "So what is the privileged language? and why is it if you were putting emojis in an essay, I would tell you that you shouldn't do that, right? And are we kind of moving past the point where I should say that, right?" (Jack, interview, 10/18/18) 
Talking about linguistic privilege, especially in a predominantly white institution like NCCC can be very difficult; however, in this excerpt, Jack demonstrated how the use of a relevant reference like emojis makes difficult topics, like linguistic oppression as a form of racism, accessible. Further, Jack let students guide the discussion, as they were the experts in the room when it came to the nuanced symbolism of heart-emojis. This move positioned students as knowledgeable contributors to the discussion and the class community, and it showed how Jack's reliance on students' knowledge and the use of relevant examples was both engaging for students and artful in setting up the more difficult discussion of privileged language. The question he posed at the end of the excerpt ("are we kind of moving past the point where I should say that [they should not put emojis in an essay]") showed critical questioning of academic discourse and how writing conventions change over time, an idea that is one step in laying the foundation for developing critical consciousness. These examples illustrate how relevant, relatable pedagogy can create the conditions for empowering students.

Humanizing feedback through in-person writing conferences. While giving feedback to students on essay drafts is a standard practice in teaching composition, data in this study emphasized students getting in-person, verbal feedback as an empowering practice. The primary source for feedback were the instructors themselves. Amy, Jack, Judith, and Leny all required in-person conferences where they could talk and give 
direct, detailed feedback while the student took notes. After students had completed their first drafts and finished a round of peer review and revision, Amy described:

Then of course the day of the conference... I take them [essay drafts] all. I stay. I print them. I staple. If they gave me a revised one, I staple it to the one before because I want to show them that there's progress, right?...Okay, now, they meet with me and this is where it all-- This is the most important part after where they hear each other's stuff. I talk to them. I say, “Okay, here's what you have. How are you going to support it?" (Amy, interview, 10/12/18)

The in-person conferences allowed Amy to work collaboratively and interactively with students in the revision process. She uses a conference record sheet where students take notes during the session (Amy, course materials), which forces students to actively think about the feedback and interpret how it applies to their writing. The detail of, "I stay. I print. I staple," reflects the care and intent behind each action. Even the act of stapling has a purpose, "to show them that there's progress." The interpersonal quality of the writing conference humanized the feedback process and content, helping students to understand their writing and the feedback not as discrete tasks or products, but instead as interactive communication between people. Rather than students being passive receivers of written feedback, Amy and the other participants mentioned above felt that the face-to-face conference allows students to take an active role in articulating, 
explaining, and reconsidering their writing choices, creating an opportunity for students to take ownership of their writing and become agents in their education.

These participants also described that in-person conferences had the benefit that instructors could communicate more feedback more efficiently than if they had provided written feedback alone, and it allowed them to check students' understanding repeatedly. Rosina stated, "I feel like my written feedback is just part of a larger conversation that I'm having with the individual student when they're working on their papers" (Rosina, interview, 12/19/18). She described that the "larger conversation" was occurring in mostly during class or office hours in unscheduled talks rather than in scheduled conference times. This guiding talk supplemented the written feedback students received from her and from classmates during peer review.

Four of the participants identified in-person conferences as being particularly valuable for English language learners (L2) because it enabled them to check student understanding of feedback, to ask exploratory questions to help students with idea generation, and to answer questions for students (Amy, Judith, Leny, Rosina). In addition. Leny described how the in-person conference enabled her to establish personal connections with her $\mathrm{L} 2$ students:

I usually meet with those students in the beginning of the semester to go over their paper, and I usually always say-- I empathize with them, and how hard it must be to learn a new language, and then have to write at this level, and that I 
couldn't even do it. My colleagues couldn't even do it. [I want] to really let them know that I don't think that they're dumb. I know that they're really doing something almost impossible. Then I say, "You can succeed. You'll need to do these different things. You'll need to take your papers to the writing center. You can visit me every step of the process of the writing paper, of the essay." (Leny, interview, 2/4/19)

In addition to establishing interpersonal relationships as a foundation for learning, the face-to-face conference allowed Leny to validate language minority students by saying directly, "You can succeed"; validation, especially from instructors, helps foster a sense of belonging, builds confidence, and supports success for students of color and English language learners (Rendón, 1994; Wood, Harris, \& White, 2015). Following up with the recommendation of resources, the writing center and the instructor, illustrates how the conferences create an opportunity for providing support that is tailored to individual student's needs.

Participants felt the benefit of in-person, verbal feedback was not limited to instructor/student conferences. All participants in the study actively promoted the use of additional writing supports beyond the instructor. Rosina explained, "So peer review to me...could be an equity practice. I mean, because I want them to feel as though they have-like, authority is more disperse, right? It's not just me. Like, I'm not the only one who can read your draft and offer a feedback. Like your classmates can do that too" 
(Rosina, interview, 10/11/18). Getting feedback from multiple sources, especially if the feedback is conflicting, forces students to make choices about what to keep, cut, or change in their papers. That decision-making empowers students as writers, and promoting the use of in-person feedback sources maintains the humanizing aspect of feedback and writing. Course syllabi show that two participants required visits to the Writing Center and allotted points for the tutoring sessions (Amy, syllabus, Fall 2018; Rosina, syllabus, Fall 2018). Other participants recommended visits to the Writing Center and meetings with an embedded class tutor (Jack, syllabus, Fall 2018; Judith, syllabus, Fall 2018). The ubiquity of instructor promotion of additional face-to-face feedback sources suggests that the department and the college endorse structured supports by funding programs like the Writing Center and the embedded tutors program.

Building relationship-centered classes. (Spotlight on Leny). With six years of college teaching experience at both the college and developmental level, Leny is the participant who is newest to teaching. She described her background as being important to her ability to relate to her students, especially in developmental classes. Describing herself as a "terrible student" in high school, she was placed into developmental classes that "felt stupid and demeaning, and I was bored... so I started doing the work" (Leny, Interview, 12/4/18). When she began to do well, her teacher moved her to a higher-level class, “but I couldn't succeed. I couldn't succeed because...I didn't have equity. I 
didn't have the support in equity. They just expected that I would catch on and know how to do all the things that they knew how to do. And so I failed" (Leny, Interview, 12/4/18). Here, Leny identified that having access to the "higher-level class" was not sufficient; despite her intellect, she needed additional support to make up for what her prior educational experiences had not provided. This personal experience deeply shaped Leny's teaching philosophy. With graduate education in literature, Leny described that thinking about equity as it is talked about now in relation to $\mathrm{AB} 705$ was new to her, but that "it made sense" to her because of her background.

Even though Leny has been teaching for a relatively short time, she described that her teaching in developmental classes has evolved into a relationship-centered practice. She described how her teaching has changed:

Over time, I think I was much more of an authority figure in the beginning. If there was any disruption ... I wasn't used to disruptive behavior at all in classrooms, so there was a lot of it happening, so I just kind of became ... I wouldn't say iron fists but kind of ... "You act this way, or you leave my class," that kind of thing. And I've really changed that a lot. I feel like I have more empathy for the students. I know there's a story behind that behavior. That's the difference... I'm looking more at myself than at them when there's behavioral issues. If there's a behavioral issue, I know how I want to react. I have to take 
more time to self- reflect and to see what buttons are being pushed in me that are my responsibility. (Leny, interview, 2/4/19)

As a new instructor, Leny coped with unexpected behaviors with more control "as an authority figure," where she set strict limits and consequences, as evidenced in, "You act this way, or you leave my class." Time, experience, and critical self-reflection allowed Leny to see how her role in her relationship with her students affected both instruction and learning. An authoritative instructor holds all the power and controls all aspects of the classroom; however, the excerpt above shows how Leny relinquished her authoritative persona by becoming more aware and thoughtful about her own emotional behavior as she takes "time to self-reflect and to see what buttons are being pushed in me that are my responsibility." Her self-reflection is what enabled her to shift from authority and control to building relationships.

As she moderated her own behavior, students participated more, and the behavioral issues disappeared. She traded an authoritative teacher persona for a more empathetic, supportive relationship with her students. Leny reported:

Like, I still have the rigor, but I come, I get to them first. I feel like that's the most important thing. I get to them first, to get to the humanity of, of what I'm doing first. And then when I get their trust, then I can teach all this other stuff. (Leny, Interview, 12/4/18) 
In "getting to the humanity" of teaching, Leny is relying on the personal connections she builds with students as the foundation for education. In the relationship-centered classroom, authentic care and support foster a sense of acceptance and trust, which allows students to be more open to learning (Rendón, 2014; Valenzuela, 1999). This openness sets the conditions for empowering students, especially as Leny let go of some control and trusted students to assume responsibility and ownership. Leny talked extensively about using active listening as a major tool for building trust: "I really acknowledged them during discussion. I really honor what they say, and I really just, it's very like personal, you know. Like, I see you, I hear what you're saying, and this is what's cool about what you just said" (Leny, Interview, 12/4/18). She also described using active listening in particular with English language learners in office hour meetings and in class discussion because it is important to her that they feel like they have a voice. She communicates direct, positive messages of support and belief in their ability to succeed in the class.

Co-constructing the class with students. (Spotlight on Judith). Judith has an MA in Composition and has been teaching developmental and college-level courses for 10 years. She is a full-time, tenured instructor at NC, and she taught previously as an adjunct instructor in Southern California. She identifies ethnically as White with a middle class upbringing in a conservative family, but her perspective on equity in education is deeply shaped by her identity as queer and lesbian, and by having 
formative years of her identity take place in a racially diverse, urban high school that was openly racist and biased against students of color. The personal, daily witnessing of racism and the effects of educational inequity shaped Judith's view of teaching as a political act, what she called, "the most profoundly radical act there is" (Judith, interview, 10/9/18). Within the NC English department, Judith was one of the instructors who piloted the accelerated course, and she has taught for several years in a learning community that was established through the college's HSI grant to support Latinx and Hispanic students.

Judith's positionality belies her philosophy on teaching composition. She, like the other participants, sees writing as a powerful act, and therefore she sees the teaching of writing as a practice of empowering students through their writing. For Judith, this means creating a learning environment with - not for - her students. Judith described how, after she received tenure, she made a lot of effort to shift the power dynamic of her courses. She said:

I just started honestly looking at the minutes of my class and really realizing that I think I'm like this, but I'm actually like this, you know? Like, I like to say that I'm giving up the power in my classrooms, but the more I learned about ways to give up -- not to replace content, but ways to replace the power dynamic... with more equity... It was this tremendous amount of pressure to, like, fill up [the class time]. And then the more I just kind of really reflected on how many 
minutes I was spending teaching and how...there was a disconnect between what I was thinking my values were and how it was playing out in my classroom. So, I've... really tried to go as wild with that idea of co-construction as possible. (Judith, interview, 10/9/18) (emphasis in original)

In this excerpt, when Judith says, "I think I'm like this, but I'm actually like this," the first "this" refers to her perception of her instruction as being student-centered, and her realization that she was not enacting equity in the way that she wanted. In order to "replace the power dynamic... with more equity," Judith wanted her students to be as active as she was in the creation and construction of the class. This kind of coconstruction is rooted in culturally responsive pedagogy, which places the responsibility for learning on instructors to create the optimal learning conditions (Gay, 2013). Every decision Judith makes is intentionally crafted to maximize student involvement, engagement, and interest in the class. Everything from "Classroom values" (Judith, syllabus, Fall 2018) to writing assignments are negotiated by students. For example, if an essay is worth $10 \%$ of the class grade, Judith and the class negotiate together how points will be allotted for grading (e.g. 10 points for thesis, 25 points for development) (Judith, syllabus, Fall 2018). In another example, Judith described that the students chose to read The Beautiful Struggle by Ta-Nehisi Coates aloud together in class rather than alone outside of class. Her role is to create the learning opportunities, to be flexible, and to guide when necessary. 
The importance of co-construction in Judith's class is rooted in her value of empowering students as an equity practice. She described her students, saying, "They love to write, and they love to read, and they love to talk about writing and reading. They're nerding so hard, but they have ... they've just had these, like, brutal ... They've been brutalized" (Judith, Interview 2, 12/19/18). Where educators with a deficit view of student ability would assume that students ended up in developmental English because they hate reading and writing or because they don't care or because they lack the capacity to do college-level work, Judith sees her students from a positivist perspective, that "they love to write, and they love to read." However, when Judith says, "they've been brutalized," she is referring to their prior educational experiences, the experiences that funneled them into developmental education. Of one student in particular, she said, "She loves to read, she loves to write, but she's in fucking remedial. It's absurd. You can't believe it. Her academic identity...there's a huge mismatch between her skills, her joy for education, and the messages that she's got from teachers and our placement exam and otherwise. It's awful" (Judith, Interview 2, 12/19/18). Judith's word choices, "fucking remedial" and "absurd", reflect her outrage at the injustice she sees in the way this student has been treated. Judith thinks "the messages" the student has received in her prior education are messages of oppression - that she is not college-ready, which is what placement exams are supposed to determine, despite "her skills, her joy for education." Judith understands that students ended up in developmental classes because 
of systemic and instructional inequity. Her use of co-construction and critical pedagogies gives her a framework for attempting to correct harms from prior educational experiences.

\section{The Relationship of Equity to Perceptions of Rigor}

This class is about, the main thing this class is about is pushing yourself as a thinker, and writing is one of the ways we do that. Writing is really just a way for us to ... It's like going to the gym for your mind. It's a way of exercising your mind and trying ideas out. I tell them that in all my classes, too, and I felt like at least for a certain percentage of students it takes some pressure off when they undersiand the word essay comes from the French, the verb essayer, to try, to attempt. (Scott, interview, 12/20/18)

The second finding of this study is that participants perceived equity-oriented pedagogy as being enmeshed with - and often in opposition to - departmental discussions of rigor. Academic rigor is one of the defining features of higher education. Schnee (2008) defined rigor as, "deep, critical, inquiry-based learning that pushes students to new levels of academic accomplishment and recognizes the importance of sufficient scaffolding for all students to reach high standards" (p.64). It is the assurance that the work done in college will change how students think, that the work will be hard and that the learning will also be supported. When asked about rigor, five participants in 
the study talked about rigor in this way, as is reflected in Scott's excerpt above. Rosina echoed Scott's take on rigor in composition classes, saying:

To me like right off the bat, it [rigor] means thinking. It has to do with thinking and critical thinking and having, like, interesting, fresh insightful arguments about relevant topics that you could go out and, like tonight at dinner, talk to people about... It's like an argument about something that matters. I feel like the medium is writing, but it's thinking. I mean, writing is thinking. (Rosina, interview, 10/11/18)

Both Rosina's and Scott's views on rigor complement Schnee's definition. Most participants had similar takes on this view of rigor (Jack, interview, 10/18/18; Judith, interview, 10/9/18; Leny, interview, 12/4/18).

Data from half of the participants, however, suggest that connotative meanings of rigor have emerged as it has been discussed in the department. These connotations impact both instructional choices and departmental culture. The participants in this study are operating as embedded cases within the English department context, so the department culture regarding rigor can have influence over curriculum, assessments, and even evaluations. Participants offered three main critiques of connotative associations of rigor, where rigor was associated with: 1) being rigid; 2) achieving correctness in "standard English;" and 3) suffering. 
Critiquing rigor as being rigid. As mentioned earlier, Judith makes great effort to make her classroom an engaging, relevant, and interesting space for students. However, she found herself being maligned as an "easy" teacher by colleagues, attributed entirely to how engaged her students were in her class. She talked about repeatedly receiving the message that, because her students were having fun, then her class must be easy. She reported overhearing this message in a conversation between colleagues early in her career at NC, and stated that she heard this conflation of "engagement" with "being easy" echoed repeatedly over the years, most often during discussions of how the department values and promotes rigor (Data memos 10/30/18, Field notes, 5/4/18, 2/7/19, 3/7/19). Her description suggests that, where engagement is equated with being easy, rigor is equated with being rigid. Judith critiqued:

What are we measuring when we're measuring rigor? ...the way that I would measure it would be in terms of their writing process... There was a cool concept I'd never heard of, threshold concepts, for, like, things that if you don't master, you're not going to make it essentially, in that field. And [in composition] it was "writing is a process" and "writing is collaborative." To think of those things as threshold concepts means you need to measure them, so they like get points for meeting with a tutor or for going to the Writing Center... or for meeting with a research librarian, things that challenges their comfort, that challenges their intellectual dexterity. So like, that's how I kind of navigated 
that. It's really - and I just thought a lot about, like, the coded language we're using, you know, to reinforce white, middle-class, first-language, English speaking norms. (Judith, Interview, 10/9/18).

Judith defined threshold concepts in composition as "writing is a process" and "writing is collaborative." Although the threshold concepts Judith mentions might be commonplace ideas in composition theory, facilitating students' achievement of those concepts is challenging, especially since many students enter college thinking of writing as a product. Getting feedback from a tutor, making decisions about what to change in an essay, and adapting to audience's needs all challenge students' "comfort" and “intellectual dexterity." If these challenges help students to attain the threshold concepts of composition, then Judith argues the class is rigorous. Further, Judith's framing of rigor as gaining threshold concepts is consistent with Schnee's (2008) definition, where students' critical thinking is pushed to a higher level and they are supported in the process.

At the end of the excerpt above, Judith referenced "coded language" of "white, middle-class, first-language, English speaking norms." When rigor is defined narrowly as teaching students to write "standard English" (Greenfield, 2011), instructors like Judith are pushing back against racialized conventions of academic discourse. The measure of meeting "standard English" is adherence to grammatical conventions of White, Western academic language. Judith commented: 
I think we spend so much time being punitive about rules and regulations and standards that it just becomes dehumanizing. We're a whoie bunch of really privileged people who don't have the same experiences that a lot of our students have, and I think that just because we made it, somehow we're now the gatekeepers that are gonna hold to these rigid - That's not the world I want to live in. (Judith, Interview, 12/19/18)

Judith uses the collective pronoun "we" to refer to English instructors who value correctness over content and who are "punitive about rules and regulations and standards." Judith critiques this form of "rigor as rigidity" as being a form privilege, of instructors holding power over students based on their language privilege and punishing students who do not meet the rules of Standard English. Judith argues that students are oppressed by a strict association of rigor with difficulty of a course or with rigid standards of grammatical correctness over idea development and critical thinking. This idea is extended in the Spotlight on Rosina.

Critiquing rigor as achieving correctness in "standard English." (Spotlight:

Rosina). Rosina is an adjunct (part-time) English instructor who holds a Ph.D. in Linguistics. She has taught for eight years in higher education, the last two of which were at NCCC, where she regularly teaches the Linguistics course in the English department along with the college-level composition course. Her experience teaching developmental English is recent, only since she was hired at NCCC. Even with limited 
experience at the developmental level, her description of her philosophy and pedagogy reflect an equity orientation. She holds no additional positions in the department and does not sit on any committees, but she regularly works as a faculty advisor in the Writing Center in addition to her teaching work, and she has been an active participant in the department's discussions about the AB705 transition over the past two years.

Like the other participants, Rosina also questioned how rigor was being discussed in the context of the English department. As a sociolinguist with expertise in the structure of language as it relates to cultural and social factors, a major critique Rosina raised was centered around how she felt the department communicated rigor as maintaining an ambiguous "academic standard." She reported:

When I hear those kind of standards ... I mean, it just sounds like a gate keeping function. It all just sounds like, "Here are these sort of arbitrary levels, and if you can't reach that, then you can't join the level that I'm at." I mean, I understand that...English classes are places where people should be building up their strategies for how to be a more effective writer, but I feel like when I hear "standards"... people are just talking about prescriptive ... this kind of supergeneric academic language, that I'm like, “Oh, but it just doesn't exist in the world really." Standards should be questioned and interrogated. I think that you have to find a way to help them [students] develop their voice in that prescriptive way, because it's powerful. I mean, it can do things for you in the 
world ... but you can't just teach standards without also teaching critique of standards. (Rosina, Interview, 12/19/18).

While Rosina acknowledged that there are patterns, rules, and guidelines when it comes to writing, what she referred to as "strategies for how to be a more effective writer," she critiqued the idea that there is a single, uniform definition for "standard English" or "standard academic language." From the linguist's perspective, all language is culturally bound, dependent upon the shared use and norms of the people using the language, so to identify a particular variety as a standard that "doesn't exist in the world, really" implies a privileging of that variety to the detriment of other varieties. Rosina is not saying students should not be taught grammatical rules or sentence structures, for example, but she is arguing that "standards should be questioned and interrogated." Rosina gave an example where students, who were writing a narrative essay, were questioning how they could write it without using first person voice:

They were like, “Well, I can't use 'I'. My [previous] instructors were really specific about that. Cannot use 'I'", and... I'm just thinking, where did that come from? Why is that a thing, you know? What is that implying to the student and suggesting? Like, your perspective is not important? I don't know. And I know that there are different genres, and maybe that was a conversation that they were having in that class. I'm like, what genre is that though? Because if this is 
academic language, in linguistics we use " $\mathrm{P}$ " all the time. (Rosina, interview, $12 / 19 / 18)$.

Rosina asserts that the use (or not) of the first person, " $\Gamma$ ", in an essay is not a generic academic standard but a discourse convention set by a discipline ("in linguistics, we use ' $\mathrm{I}$ ' all the time"). In her successive questioning of claiming this convention as a standard ("where did that come from? Why is that a thing, you know? What is that implying to the student and suggesting? Like, your perspective is not important?"), Rosina is herself interrogating the oppressive implications of this example of standardizing a convention. Greenfield (2011) argues that notions of standard English in academic institutions not only are myths unsupported by scientific understanding of language, but also are oppressive to linguistic minorities. In other words, when a discourse convention, linguistic variation, or grammatical accent is reified to the point of becoming a "standard," then "nonstandard" conventions, variations, and accents are inherently categorized as deficient and wrong. Rosina's critique echoes Greenfield's argument.

Critiquing rigor as suffering. (Spotlight: Jack). Jack has been teaching in higher education for eight years since graduating with an MA in English for Teaching Composition, which focused on developmental education. He started teaching in the NC English department as an adjunct instructor and was hired into a fulltime tenure track position four years later. From the start of his career, he consistently elected to teach 
developmental classes every semester, unlike many instructors who might only teach developmental classes if no college-level courses were available. Like Judith, Jack was another instructor who embraced acceleration and other innovative teaching practices that were intended to improve outcomes for students in developmental classes. As the department has prepared for the implementation of AB705, Jack led the group who developed the curriculum for English 50, the new co-requisite support course for students taking the college-level composition course but whose placement indicates they would benefit from support (the students who would have been placed into developmental classes prior to AB705). He is also leading a faculty Community of Practice group to support instructors who will teach the new English 50 course in the fall.

Jack described his young self as a student who loved learning, and who benefitted from tremendous privilege in having access to some high-quality education in special advanced classes, but this access did not make him immune to the mediocre education available in a majority of classes. In high school, he applied for and was tested into a special advanced program, which he entered mid-year. He loved his advanced program, which utilized hands-on, problem-solving, and inquiry driven pedagogy to create challenging, rigorous, and engaging work. Having come from regular classes, Jack described this program as creating a sharp awareness of injustice because he kept thinking about the students in the "mainstream" class and how "boring" 
it was and how much they were the ones who really needed to have engaging learning experiences. These early experiences sensitized him to ways instructors and education can harm students, despite good intentions.

One of the ways students are harmed is when rigor is associated with suffering. As mentioned previously, rigor has been poorly defined but is often associated in the department variously with "standard academic writing" or hard grading with a rigid emphasis on grammatical correctness in writing (Field notes, Spring 2018, Fall 2019). Although rigor is ostensibly a positive attribute in higher education, Jack felt that discussions of rigor within the department had been particularly problematic because of its association with suffering:

I think that for a lot of people, rigor is connected to suffering, and I do not believe in that. I think that that's not my job, to make them suffer. They can work really hard and still find joy in that [learning], and still find play in that, and still produce really solid work.... There is rigor in the course, there's a lot of work, but I do work very hard to detach suffering from that. I think students can learn how to be really great readers, reading something contemporary, exciting, and evocative or even salacious. (Jack, Interview, 10/18/18)

Like Judith, Jack has encountered overt questioning of the rigor of his course from within the department because his students seem to enjoy his class. He rejects this public misconception, saying, "for a lot of people, rigor is connected to suffering, and I 
do not believe in that." From Jack's own experience with traumatic anxiety in school as a youth, he feels strongly that education should not be traumatic ("that's not my job, to make them suffer"), especially "in light of everything we know about our brain and what stress does to learning" (Jack, Interview, 10/18/18). In Jack's experience of teaching developmental English, rigor is a resuit of the sum of work that should be challenging and still engaging; Jack asserts it can sometimes even be fun when he says, "They can work really hard and still find joy in that, and still find play in that." None of these qualities means that students are not being challenged. Graham and Essex (2001) assert that rigor is comprised of challenging work with high expectations that pushes students' critical thinking and cognitive development. Their definition resonates with Jack's perspective that students are best challenged when the course material triggers strong feelings that give students a starting point for response, as suggested by Jack's description of readings being "exciting, and evocative or even salacious."

The harm of rigor being perceived as suffering is not limited to students. Jack also identified instructors as being harmed by this association:

I think that we privilege suffering. I think you see it across the discipline. You see it in teaching, not just for these students...Like, if an instructor isn't in pain, they're not doing their job correctly. I'm curious how far we could take that. Like, if I'm not miserable in my marriage, I'm not marriage-ing well? Like, how far do you go with this? (Jack, interview, 10/18/18) 
Jack's comment illuminates the idea that if rigor is associated with instructors' suffering, then the suffering has become a proxy for measuring effectiveness, that "if an instructor isn't in pain, they're not doing their job correctly." In such a culture as this where suffering is privileged, as Jack perceives it, that suffering and stress become normalized ("I think you see it across the discipline"). He points out the absurdity of correlating rigor to suffering by extending the argument outside of education when he says, "if I'm not miserable in my marriage, I'm not marriage-ing well? Like, how far do you go with this?" In his second interview, when talking about connecting students to resources across campus, Jack commented, "So I called in sick last week because I had to catch up on grading, and I had an eye twitch because I was so stressed out trying to catch up on everything" (Jack, interview, 12/20/18). Although Jack made this comment related to another topic that was unrelated to rigor, this offhanded remark reveals that the stress and workload of teaching that would cause him to "call in sick...to catch up on grading" is pervasive and normalized. This stress led directly to Jack's physical suffering with an eye twitch. This example from his own teaching experience demonstrates how problematic equating rigor with suffering can be for instructors' mental and physical health.

\section{The Contentiousness of Equity}

We're educators. We educate, and we should educate each other rather than throw stones at each other, because, I don't know. It boils down to that whole 
thing of, we have to check our own triggers, what's getting triggered. (Leny, interview, 2/4/19)

The third finding of this study is that participants described the integration of equity-oriented pedagogy within the context of the department as being contentious. The NCCC English department, like many English departments in California community colleges, has been embroiled in debate during the past several years - over AB705, over student success data, over acceleration, over curriculum, over so many issues. The underlying current is an interest in improving equity by supporting underserved students who have experienced disproportionate negative impact. However, as the literature on equity-oriented policies and practices suggests, there are many ways to support equity, and not all of those ways are in concert with each other. Although this study looked at individual instructors' thinking and practices around equity, the participants are embedded in the larger context of a department in transition of both policy and paradigm.

All of the participants spoke to some degree of tensions playing out in department discussions related to equity, inequity, and pedagogical practices. In the opening quotation to this finding, Leny revealed feeling that members of the department have "thrown stones" at each other over departmental "triggers." These triggers are points of tension in department discussions about equity and how to best implement equity-oriented practices in the wake of $\mathrm{AB} 705$. Although the tension points may have 
been brought to the surface by $\mathrm{AB} 705$, they speak to deeper questions, not about instructors' capacities to teach effectively, but about instructors' abilities to enact their capacities within the context of the department. Participants identified three specific tension-points: 1) mixed feelings about the potential of $\mathrm{AB} 705$ to effect positive, equitable change; 2) the necessity of addressing racial inequity; and 3) inconsistency in defining equity.

Mixed feelings about AB705's potential for change. Two participants expressed being optimistic about the curricular, structural, and potential instructional changes that will result from $\mathrm{AB} 705$ implementation, but that optimism is tempered by questions they have about the transition. Scott has made many changes in his teaching in the past nine years that he has worked at NCCC as a result of his professional learning about equity. Yet, he realized he still has more growth and learning to do: "I've kind of... had the idea that I don't know what I'm doing, and so I don't have any real personal investment in any of my pedagogy or my assignments. So, I'm ready to throw any of it out the window or try something new" (Scott, interview, 12/20/2018). With no ego or defensiveness, Scott demonstrates that even a veteran instructor with twenty years of teaching experience can adapt to the new inclusion model. The years of knowledge and expertise he has won't actually be thrown out; rather, he can be more discerning about what practices to keep and how to reframe practices through the lens of equity. 
Despite uncertainty about what the college-level classes will look like starting this fall when the developmental pathway has all but disappeared, Scott was still hopeful about the success of this reform. In considering how instructors and the department will respond to the broader range of student skill level expected in the college level courses, Scott said, "I think that's going to be potentially a huge challenge, but I also feel just my basic philosophy with all of my students...if you give them a challenge, most of them are going to grab for it....They may struggle, but they'll be able to do it" (Scott, Interview, 12/20/18). Scott shows a persistent, prevailing belief in students' ability to learn, "they'll be able to do it" to rise to the challenge of transferlevel English with proper support. This strengths-based perspective of students is an essential component of equity-minded instruction.

Leny was also optimistic about the coming changes, and she identified several of her teaching practices as being equity-oriented, designed specifically to assist students who need more support, including individual meetings/tutoring sessions with English language learners and offering workshops outside of class time if students ask for more help (Leny, interview, 12/4/18). She was overt in her commitment to support equity; however, she is also uncertain of how the inclusion model will play out this fall, saying, "I'm a little suspicious of it, to tell you the truth, because I haven't done it yet. I don't understand it $100 \%$. I do believe in this idea of trying to meet students where they're at. This whole equity model makes sense to me...I want to be an equitable 
instructor, but I'm struggling" (Leny, interview, 2/4/19). Leny's "suspicious" feeling and her "struggling" with the inclusion model show her uncertainty with how equitable instruction can and will actually play out after implementation. While pragmatic equityoriented practices are more easily adopted, such as incorporating UDL principles, soliciting student input on text selection, or choosing topics that are relevant and relatable to student lives, Leny felt that many of the equitable practices she had adopted, or that she would like to adopt, are unsustainable. For example, meeting individually to work with ESL students on building writing skills and language skills takes time. She asserted, "I have all these good intentions, but I am going to run myself ragged trying to implement equity in a really good way. So, it's not just about having an equity value. No, it's being able to have equity in our practices that are sustainable" (Leny, Interview, 12/4/18). Sustainability is achieved when outputs and inputs are in balance. If Leny is "going to run myself ragged trying to implement equity," that balance is lost. Leny explained that when she thinks about equity, she thinks about her own experience in high school of having the intellectual capacity but not the skills she needed. Now as an instructor, she thinks about what supports her students need to be successful. At this point, she is not yet convinced that $\mathrm{AB705}$ and the department's response will adequately provide what instructors need to support students in ways that can be sustained over time. She worried that this would lead to the pressure to "dumb down" 
curriculum or inflate grades, a worry that has been echoed throughout the department's discussions of AB705 impiementation (Field notes, 2/7/19, 3/7/19, 4/4/19).

Although Leny sees the merits of $\mathrm{AB} 705$, she also found the split in the department between folks who support and oppose AB705 problematic. She explained, "I think because I'm straddling both sides right now, all I can say is what offends me about both sides. What offends me about it [the AB705 equity discourse] is the deficit is in the teacher. It's like, we're all professionals. We spent years going to school, getting to this place, and then suddenly this whole other system is coming where it's going to impose upon us to get retrained. It's a retraining. Forget that!" (Leny, interview, 12/4/18). This excerpt reflects the emotional response many instructors have had (Field notes, 8/18-3/19). In her declarative "Forget that!" Leny shows her frustration and exasperation with how she felt the presentation of research on developmental education was deprofessionalizing ("the deficit is in the teacher") and offensive to the years of experience and education that instructors have put into teaching composition, as it would "impose upon us to get retrained." Further, the greatest inequities that instigated $\mathrm{AB} 705$ are racial inequities, that by definition is systemic racism. This message, however, has also not been effectively communicated, from Leny's point of view: "We're living in this really charged political climate about racism. It just starts to feel like you just want to keep your mouth shut, because you don't want to say something that somebody's gonna accuse you of being racist even if you're not" (Leny, interview, 
12/4/18). Important discussions of disproportionate impact and racial inequities are lost in "the political climate about racism." Rather than see the discussion of racial inequity objectively, Leny describes an emotional, defensive reaction: "You just want to keep your mouth shut, because you don't want to say something that somebody's gonna accuse you of being racist even if you're not." Messages about systemic racism are often heard and interpreted as personal accusations, which individuals can deny; however, Bonilla-Silva (2006) argues that such denials and claims of colorblindness in the face of evidence of systemic racism contribute to the perpetuation of racism.

The necessity of addressing racial inequity. As the last quotation from Leny above shows, raising questions about systemic racial inequity often triggers defensiveness and fear about being called racist. Despite the goal of AB705 being to correct racial inequities in developmental education, Judith talked extensively about what she felt was a lack of cultural competence and racial literacy in the department. When asked how she thought the department talked about equity and practices that support students of color, she replied:

That's the conversation our department refuses to have. There's a fierce commitment to norming... Why is there no commitment to thinking about, even talking about how our department reproduces inequity?... We talk about disproportionate impact, right? And it's like, your eyes glaze over. Nobody wants to talk about disproportionate impact anymore. We all know the 
placement exam has disproportionate impact on-- But if you start replacing that language and you start using language like "decolonizing" or "desegregating the pathway", or that we're reproducing white supremacy essentially in our department with our placement practices... I do feel like... "we need to increase diversity" is a way of saying "we need to decrease white supremacy," right? But we're being polite about the language. So, when I said that, when I said something about, "if we look at who we are graduating and who we are placing where, our department reproduces white supremacist results." And one of our colleagues, like, we had the agreements about "oops" and "ouches," so she politely raised her hand and said that I "ouched" her because I called her a white supremacist. Right? And I would agree, we probably don't have any white supremacist individuals in the department, but yet, somehow we've reproduced these results in our hiring. We can't argue with what our department is reproducing. In fact, we can. The reason we're not talking about it is because we're not looking at it. So, part of that is, when I think about the things that we don't want to talk about and don't want to look at, that. We don't want to look at data... So, I do feel like that's the only conversation the department wants to have is that deficit, like what students are missing and how we can give them what they're missing...We haven't really, we have not done as a department or as individuals, particularly, not any guided critical self-reflection about how we 
can be better teachers and how we can be a better department that serves all groups. (Judith, interview, 12/19/18)

In this excerpt, Judith expressed frustration with what she felt was a pervasive willingness to avoid talking about racial inequity ("that's the conversation our department refuses to have") and what systemic racism looks like. Her excerpt also reveals that some, perhaps many, faculty in the department have reached an exhaustion point, as seen through "their eyes glaze over" and statements of "we don't want to look at data." NCCC has historically been a predominantly white institution settled in a predominantly white community. However, in recent years, especially due to the growing Latinx population in the county, the student demographics are changing; the two largest student populations are White (47\%) and Hispanic (34\%) (Student Success Scorecard, 2018). Yet, Judith observes that faculty may acknowledge "disproportionate impacts," but some refuse to directly address racial inequity and how systemic racism is perpetuated: "I said something about, "if we look at who we are graduating and who we are placing where, our department reproduces white supremacist results." And one of our colleagues... politely raised her hand and said that I "ouched" her because I called her a white supremacist." The repetition of "we don't want to look at" and "we don't want to talk about" illustrates Judith's frustration with what she sees as a willing ignorance of systemic racism. Judith explains that it is easier for instructors to focus on a deficit view of "what students are missing and how we can give them what they're 
missing" rather than facing their own complicity in a racist educational system. Her final comment in the excerpt suggests that the department would benefit from critical self-reflection that presumably would include racial literacy. The idea of critical selfreflection is further explored in the Spotlight on Scott.

Inconsistency in defining equity. (Spotlight: Amy). Amy has been teaching English at NCCC for six years, and she has worked previously as both a full-time tenured English instructor at another community college and as an adjunct instructor, for a total of nearly twenty years of teaching experience. Holding her TESOL certificate, Amy also has experience teaching English abroad as a foreign language. Within the NC English department, Amy has been an active member of the faculty union, whose leadership largely has been critical of the educational reforms supported by the Chancellor's office, including the acceleration movement, AB705, student selfplacement, and guided pathways (Field notes, Sp 18, Fall 18).

Five of the participants understood educational inequity as a disproportionate disparity in educational opportunities and outcomes for different groups of students, especially by race, gender, and socioeconomic status (Bensimon et al., 2016). As a corollary to this definition of inequity, equity in teaching is defined as creating the circumstances necessary for all students to be successful despite any past exclusionary experiences (Bensimon et al., 2016). Like several of the other participants, Amy felt strongly that the work "of community college is equity" (Amy, Interview, 10/12/18) 
through the open access guarantee, yet her definition of equity was not consistent with the other participants or with the literature. Amy's conception of equity is tied to the historical origins of remedial education. Regardless of skill level or past experience, people can have access to college education at a community college; remedial education is the solution to the open-access "problem" of students coming in to college with varying skill levels. Amy stated emphatically, "For me, I see remediation as more time with words. Period" (Amy, interview, 10/12/18). With a background in teaching ESL, Amy aligned the language acquisition process, which happens incrementally over time, with the process of learning academic reading, writing, and critical thinking for college.

The logic in Amy's thinking then is that equity work is developmental education, and that developmental education means more time with words. Thus, Amy sees educational reforms that target a shortening of the time to completion to remove exit points ( $\mathrm{AB} 705$ and acceleration) as inequitable policies that rob students of the time they need to gain academic literacy. In an impassioned moment, she explained:

It makes me angry because here is the student...They can't read a book... They can't read OfMice and Men by Steinbeck their sophomore year because they just got beat to death by their mom's boyfriend who's on crack cocaine. Those words never come to them. They look at texts, and they're like, "Who the fuck is John Steinbeck? I didn't have breakfast this morning." So yes, absolutely, they're marginalized in so many ways, but what happens is now, they get into 
our system, and now, we blame teachers because our pathway is too long. Are you effing kidding me? They need this time... We can't rush year to years. We just can't. All we have is three classes... And if we say, "Well, look at the outcomes. This many people fail, and of the ones who fail, look at the percentage of them who might be African American, Latino...." Yeah, unfortunately, all of that inequality happened before we ever saw them...I believe there's so much inequality. I don't believe it rests in our pathway.... This person, because of the horrible institutions that we have that don't allow this person to be the fullest that they can be for all kinds of reasons, now we're going to blame it on a pathway that just takes too long, and they eventually fail. But speeding it up will make them not fail? That makes no sense. It just makes no sense to me. And again, for me, it's logical. Give them more time. Give them more time to feel safe. Give them more time with words. We're doing them a disservice because, I don't care what anybody says: I give them simple texts, I give them challenging texts - they're not reading. They have no relationship with words, and it's not because I'm a bad teacher. They just don't feel comfortable with words; they don't read. That's the bottomline. (Amy, interview, 10/12/18) [emphasis in original]

The language Amy invokes in this passage is rooted in a deficit view of students ("They can't read", "they have no relationship with words"); however, her underlying 
definition about equity complicates the simplistic quality of "deficit view." Amy's deficit view is less about an inherent deficiency in students, and more about deficiency in students as a result of educational inequity. The mantra that she teaches students in her classes is, "Good writing equals sincerity plus meaning plus time" (Amy, interview, $10 / 12 / 18$ ), so the message of needing more time is communicated directly to her students. In this excerpt, she also identified that reading is a major obstacle for students at the developmental level - not reading analytically or reading comprehension, but the act of completing a reading assignment ("they're not reading"). This excerpt is an illustration of how Amy's conceptualization of equity, which she defined as "needing more time with words," structures her argument against AB705. Because the discourse surrounding $\mathrm{AB} 705$ is rooted in equitable outcomes and student success data, it can be easy to categorize faculty positions on $\mathrm{AB} 705$ as either being in support of promoting equity or being opposed to focusing on equity in outcomes. However, Amy is an example of an instructor who opposes $\mathrm{AB} 705$ but values equity, albeit a different conception of equity than is espoused in the AB705 discourse.

Despite valuing educational equity, Amy is conflicted about wanting to support students and feeling skeptical of instructors' abilities to teach effectively in the postimplementation phase of $\mathrm{AB} 705$. Her direct communications with students are positive statements that communicate her belief in their abilities: "One final piece of advice: Be optimistic. You can complete this course" (Amy, syllabus, Fall 2018) [emphasis in 
original], and she described working hard to combat students' negative self-talk so that they rewrite the narrative of themselves as "being bad at English" (Amy, interview, 2/11/19). However, in interviews, Amy communicated that she does not believe students can learn the necessary reading, writing, and critical thinking skills in a single semester as it structured in the inclusion model composition course. When asked directly if we can give students what they need in a single college-level inclusion class post $\mathrm{AB} 705$, she replied:

I know we have to, and we have to do this, and we have to hope for the best. People say these wonderful, beautiful things, and I get why. Because as teachers, we are always hopeful. But I think it's horrible. I think it's vulgar. I think it's a disservice. And no, we can't. But we'll try. We will try our best. And I'm very hopeful. It's mortifying to me. We're just talking around something, now. We're just dancing around it. We're going to pretend to teach English now. And in my heart, I know it. (Amy, interview, 2/11/19).

The contrasting messages between positive ("I'm very hopeful") and negative ("It's mortifying") are suggestive of an internal struggle. Despite using the word "hopeful" twice during her response, the overall effect of the message is one of hopelessness, as expressed in "it's horrible...it's vulgar...it's a disservice...it's mortifying." Amy's belief in the impossibility of adapting instruction in the new equity framework of the completion agenda leads to the inevitability that instructors are "going to pretend to 
teach English now." In Amy's view, not only will students not be able to reach the reading and writing proficiency expected in college-level, instructors are powerless to adapt teaching to meet these needs because the only solution Amy sees is "more time with words" (Amy, interviews, 10/12/18, 2/11/19), which is made impossible under the new AB705 mandates. Because of the hopelessness, Amy expressed belief in the inevitability of grade inflation and lowering standards. Her role, then, as an instructor will be to do what she can, even if it is inadequate: "My role is to make sure that they have as many opportunities as possible to express themselves in words. And that I need to provide constant feedback, so that wherever they are when I meet them, that I in some way help them become a better writer. Even if it's just a couple steps ahead" (Amy, interview, 2/11/19).

Resolving tensions through critical self-reflection. (Spotlight on Scott). Scott is a newly tenured full-time English instructor at NCCC, but he has over twenty years of teaching experience. As a White male from a middle-class family in the southern U.S., he acknowledges he comes from a privileged background, but he has dedicated himself to personal and professional growth. With a Ph.D. in American Literature, Scott has spent the majority of his career teaching English classes at the transfer-level, including freshman composition, advanced composition and critical thinking, and literature classes. When it comes to teaching composition, Scott described that over the past twenty years, he has taught the college-level composition course more than other 
English course, and he started teaching developmental English when he began working at community colleges. Within the NC English department, he was the faculty member who oversaw the grading of the student writing samples done as part of the English placement exam. When state research on the efficacy of placement and developmental education was underway, Scott was in a position to read the research and bring an informed voice to the department regarding educational reform and AB705 (Field notes).

Five participants identified critical self-reflection as the most crucial element for the department in working through the tension-points and making decisions about how to promote more equity-oriented teaching practices. Of all the participants, Scott best exemplified how critical self-reflection was essential to the development of his understanding of equity and how his view of his role as an English instructor has changed as a result of learning about equity. When asked how he conceptualizes equity, he responded:

I think my biggest struggle when I first started teaching was that I was no more than maybe 8 to 10 years older than the students I was teaching. And I didn't feel like an authority in any kind of way. And I just went in with the assumption that they must have all, you know, they had the same preparation that I had when I walked into my first English class, and I operated on that assumption for many years. And if they clearly didn't have that [preparation], then I would make 
some excuse for it or I'd say, "Well, too bad for them. Maybe they're not cut out for college," or this thing or that thing. And it never occurred to me that part of my job might be to try to account for that in some kind of way, to think about, that not everybody comes into this classroom with the same preparation, the same experience, the same support, the same life circumstances. And I guess, because of the experiences I had, I just assumed so much that that was other people's experience. And so for me, it's been about waking myself up to those experiences and seeing what I can do differently as a teacher to account for that. And it's still something I struggle with. It's still something I'm trying to figure out. (Scott, interview, 10/24/18)

Scott had to confront how his own privileged background shaped the assumptions he made about his students and their abilities ("because of the experiences I had, I just assumed so much that that was other people's experience"), despite being a seasoned instructor with years of teaching experience. When asked to define equity, Scott's immediate thinking was not about outcomes or data or research, but rather reflecting on his own growth as an instructor. This growth begins with an acknowledgement of assumptions he made about students in college, particularly that they had to have the writing and reading skills when they started or else they were "not cut out for college." He expressed regret for the students for whom, over the years, he missed some opportunities to help, saying: 
I know we have to grow as teachers, and we don't know everything we need to know when we first start teaching. There are times when I regret. ..I think I could have been of way more assistance to who knows how many hundreds of students over the last 20 years if I had known more about how to be equitable in the classroom and out of the classroom, too (Scott, interview, 10/24/18).

Scott's statement, "There are times when I regret," shows how his critical reflection allowed him to see the bias he held in assuming his students had similar educational experiences as he, and that they would learn in the same ways.

Scott explained that as he participated in professional learning opportunities that directly addressed equity and inequity in college, his thinking about his own teaching began to change. For Scott, understanding equity meant reevaluating his role as an educator:

I can say it's been a reminder to me to not leave anybody out of the equation in my classroom. To recognize that everybody needs ... Everybody has the right to learn and to grow, and that means that I have a responsibility to figure out what that is going to be for all of my students, and that's a heavy one. (Scott, interview, 12/20/18)

The major shift for Scott did not start with adopting new teaching practices; instead, Scott's critical self-reflection led him to question what is his responsibility as an educator, what is in his locus of control, and what can he do better. 


\section{Conclusion}

This study on instructor perspectives illuminated how developmental English instructors think about equity and how they implement equity-oriented pedagogical practices in the context of their department discussions about equity. Three main findings emerged from the data analysis. The first finding is that participants conceptualized equity-oriented pedagogy as the means of empowering students. The second finding is that participants perceived equity-oriented pedagogy as being enmeshed with departmental discussions of rigor. The third finding is that participants described the integration of equity-oriented pedagogy as being fraught with contention in the department. While the findings help to understand instructor perspectives, they also raise questions for this and other English departments to consider when adopting and adapting to an inclusion model of instruction in college-level composition classes. These implications and recommendations are discussed in Chapter five. 


\section{Chapter Five: Implications and Recommendations \\ Overview of Study}

California community colleges are in the final days of preparing for full AB705 implementation set to begin in Fall 2019. The ultimate goal of this major legislative reform is to correct the educational inequities for underserved, minoritized students that have plagued developmental English and math by reforming placement procedures and limiting the completion of any remediation and the college-level gatekeeper course to a single year. Although the mandates of $\mathrm{AB} 705$ are structural in nature, they have deep repercussions on instruction and curriculum. Unfortunately, the legislation was passed without the benefit of faculty input, leaving English departments and instructors to navigate the complexities of implementation under the pressure of time. Since improving equity is a major goal of this legislation, understanding the perspectives of English instructors who value equity can help illuminate how equity might be operationalized in a composition classroom. Consequently, this study sought to investigate this topic through the following research questions:

1. How do community college developmental writing instructors who selfidentify as valuing educational equity conceptualize equity as it relates to teaching developmental composition?

2. How do these instructors experience and describe their equity-focused practices for teaching developmental composition? 
I used embedded case study design to explore how six developmental English instructors think about and implement equity-oriented pedagogical practices within the context of a community college in northern California. Data sources for this study were two 60-90-minute interviews with each of six participants and instructor-produced course materials (including syllabi, essay prompts, grading rubrics, and other assignment sheets), and researcher fieid notes. Interview protocols for the semistructured interviews were developed from the literature review as well as from instructor responses. Data were analyzed using a "ground-up" approach and constant comparative methodology (Charmaz, 2014; Merriam, 1998; Yin, 2018). First and second cycle coding of over 400 pages of data yielded 42 single-spaced pages of codes. Those codes were then deduced into 15 broad categories, which then coalesced into three themes. These themes constitute the major findings of the study. Findings are summarized in Table 2.

I argue that when English instructors value equity, that value becomes embedded in their instruction and pedagogical practices; however, individual instructors themselves are embedded within a larger department, and so may be limited in their ability to enact equity if there are multiple, competing equity frameworks at work in the department. Any discussion seeking to improve equity must take account of both the individual sphere of equity discourse around instructors' work in the classroom and the 
collective sphere of equity discourse that provides the larger context for instruction, such as the department or college.

\section{Summary Discussion of Findings}

This embedded case study illuminated the thinking and experiences of six developmental English instructors who self-identified equity as a value they hold in their professional work. Their interviews and course materials provide insight into the complexity of what it means to teach adults how to write and think critically in an academic setting in ways that support learning for students' diversity in skills, knowledge, backgrounds, and experiences. Participant voices also speak to the challenges instructors face with integrating equity-oriented pedagogies when instructors are embedded within departments, working where various equity frameworks may be employed. The discussion of findings is organized by the three central findings of the study:

- Finding \#1: Participants conceptualized equity-oriented pedagogy in terms of student empowerment

- Finding \#2: Participants perceived equity-oriented pedagogy as being enmeshed with - and often in opposition to - departmental discussions of rigor

- Finding \#3: Participants described the integration of equity-oriented pedagogy within the context of the department as being contentious. 


\section{Equity as Empowerment}

The most prominent finding of this study is that participants conceptualized equity-oriented pedagogy in terms of student empowerment. All but one of the participants spoke overtly about the teaching of writing being a means of empowering students. Those participants felt that reading, writing, critical thinking, which broadly constitute the content of composition classes, are tools of teaching empowerment. Critical pedagogies describe active, problem-solving learner-centered environments as liberatory classrooms (Freire, 1972; hooks 1994), which stand in contrast to the traditional view of remedial classes that treat students as empty vessels waiting to "receive knowledge" (Freire, 1972). The empowerment that participants described illustrates the embeddedness of equity in writing pedagogy.

The participants in this study operationalized equity as empowerment in four main ways: 1) enacting culturally relevant pedagogy; 2) humanizing feedback through in-person writing conferences; 3 ) building relationship-centered classes; and 4) coconstructing the class with students. These four pedagogical practices all manifest elements of equity frameworks that emphasize student identities and the social dimensions of learning. Participants described a variety of examples that reflect LadsonBillings's (1995) culturally relevant pedagogy and its principles of critical selfawareness, cultural competence, and social critique in education. In addition, the four manifestations of equity as empowerment demonstrate the value of humanistic 
instruction that is relational and holistic in its approach to students. In-person conferences, relationship-centered instruction, and co-construction all require an investment of time. Taking the time to build relationships with students, nurture classroom community, and show interest in students' lives establishes trust and enables authentic care, which is the foundation for learning (Ladson-Billings, 1995; Rendon, 1994; Rendón, 2014; Schnee, 2014; Valenzuela, 1999). Study participants who identified equity as empowering students have taught accelerated courses and developmental courses in learning communities. Their teaching experiences demonstrate how their instruction embodies elements of various equity frameworks, bringing together both the humanistic, intersubjective elements of validation (Rendón, 2012), socialization and mentoring (Laden, 1999) in learning communities with the more cognitive approaches of integrated reading and writing (Goen-Salter \& GillotteTropp, 2003; Horning \& Kraemer, 2013; Keller, 2013) and "just-in-time" remediation for reducing errors (Delpit, 1995; Hartwell, 1985) in acceleration.

\section{The Relationship of Equity to Perceptions of Rigor}

The second finding of the study is that participants perceived equity-oriented pedagogy as being enmeshed with - and often in opposition to - departmental discussions of rigor. While participants generally understood rigor to mean "academic challenge," three participants raised critiques of how they perceived department discussions focusing on negative connotations of rigor. These connotative meanings 
are: 1) rigor associated with being rigid; 2) rigor associated with achieving correctness in "standard English"; and 3) rigor associated with suffering. The three focal participants have created courses that are rigorous in that they are challenging, based in critical inquiry, and provide support in many forms (Francis, 2018; Graham \& Essex, 2001; Schnee, 2008). However, these three instructors were impacted by how rigor was being defined and discussed in the context of the department. These participants' experiences suggest that rigor often connotes punitive grading, an emphasis on grammatical correctness, and meeting expectations of "Standard English." Greenfield (2011) argues that, from a linguistic standpoint, "Standard English" is a myth, and that the privileging of the mythical standard in academia is rooted in racism by privileging White language as an idealized "standard." By extension, she argues, instructors who teach Standard English are espousing oppression through their instruction. Focal participants who raised the critique of punitive grading/Standard English illustrate how tacit the language of oppression had become within the department context. In addition, the participants describe that, in the department, rigor is associated with difficulty, where being rigorous means being a hard instructor. Signs of student engagement and enjoyment, then, are interpreted as "being easy," which can be threatening to future employment for part-time instructors or those in tenure review. Finally, participants also resisted the idea that rigor should be measured by the suffering of students, evidenced 
by their displeasure with their classes, and the suffering of instructors, evidenced by the sacrificing of time and health to grade endless stacks of papers.

\section{The Contentiousness of Equity}

The third finding of this study is that participants described the integration of equity-oriented pedagogy within the context of the department as being contentious. Although equity in itself is positive in promoting educational success for all students, regardless of background, the values associated with various equity frameworks make implementing equity contentious. Contention centered around three specific tensionpoints: 1) mixed feelings about the potential of $\mathrm{AB} 705$ to effect positive, equitable change; 2) the necessity of addressing racial inequity; and 3) inconsistency in defining equity. A fourth, related point was that data suggested critical self-reflection as a crucial factor in resolving these points of contention.

Participants fell on a spectrum of support for AB705. This legislation employs a framework of improving equity through improved access through placement reform and improved persistence and attainment of educational goals through shortening time to completion (Bailey et al., 2015; Cuellar Mejia et al., 2016; Rodriguez, et al., 2016). Most participants felt it would be effective in reducing disproportionate impact on students of color, first generation college students, low-income students, and other underserved student populations, though some participants had reservations and uncertainty about how instruction would be impacted by the structural change. One 
participant felt the legislation would have the opposite of its intended effect, that students who had been underserved in prior educational experiences would continue to be underserved by having limited time to practice the reading, writing, and critical thinking skills they would need before entering the college level composition course. The question of how instructional time relates to improving equity is still unresolved.

Participants also identified racial inequity and defining equity as critical points of tension in department discussions. Both of these points are essential components of equity-mindedness as a framework for implementing equitable instructional practices (Bensimon, 2007; Bensimon et al., 2012; Majors \& Ansari, 2006). Proponents of improving equity in education argue that acknowledging the systemic production of racial, linguistic, and economic disparities in education is the first step in correcting those inequities (Bensimon, 2007; Bensimon et al., 2012; Bensimon et al., 2016; Witham et al., 2015). Educators and institutions cannot effectively improve equity without clear, shared understanding of equity and the racial inequities that result from a racist system (Bensimon et al., 2016; Majors \& Ansari, 2006; Witham et al., 2015). To facilitate personal and organizational change, participants' data suggested critical selfreflection as an effective and necessary element of improving equity and resolving the points of contention.

\section{Implications and Recommendations}

\section{Recommendations for Community College English Instructors}


Because English is a gatekeeper discipline through which most students must pass, English instructors are well-positioned to positively influence both outcomes data related to student success and the holistic lives of students. The findings of this study are beneficial to community college English instructors, especially for the transitional period of AB705 implementation that may result in a wider diversity of student skills and backgrounds in the more inclusive college-level composition course. While the participants in the study self-identified as valuing equity, there may be college-level composition instructors who have not had the opportunity or support to develop an equity-orientation in their instruction that supports a wide diversity of student background and preparation. Based on the study's findings, I recommend these actions for English instructors: include culturally relevant curriculum with a holistic, humanist approach to students; center relationships and community building in the classroom; and create opportunities to practice critical self-reflection.

\section{Use culturally relevant curriculum with a holistic, humanist approach.}

Utilizing culturally relevant curriculum can increase student interest and engagement. When students from underserved and underrepresented groups, especially students of color, see themselves reflected in the authors and texts of course readings, it not only builds their own confidence, but it also shows how they and others like them have made important, valuable social and cultural contributions. Further, attending to students holistically from a humanist perspective allows for deeper student/instructor 
interactions. It also provides an opportunity for meaningful writing experiences that allow for the intellectual, psychological, and emotional development of the student. Rendón (2014) referred to this approach as "multi-human" curriculum. Rendón (2014) argues that an exclusive focus on knowledge acquisition and intellectual development is rooted in a Western, colonized worldview. The multi-human curriculum is a response to this exclusionary practice; it is rooted in indigenous philosophies that treat people as both emotional and intellectual beings. Rendón (2014) describes multi-human curriculum as being both multicultural and humanistic. It embraces multiple viewpoints and perspectives and values personal growth as much as intellectual growth. Texts and writing assignments are chosen to illustrate a range of experiences and worldviews, especially those viewpoints that are not typically represented in mainstream literature. These texts and assignments are also chosen because they are relevant to students lives.

Center relationships and community building in the classroom. Valenzuela (1999) argues that a necessary condition for student learning is the teacher's genuine interest in student lives, what Valenzuela calls authentic care. Faculty who learn students' names early, who make personal contact with students, and who share their own stories demonstrate their authentic care to students. This personal relationship allows for deeper interactions later in the semester on substantive issues, such as the inperson writing conferences described by the participants. With a relationship of authentic care and interest established early, instructors are able to communicate more 
detailed feedback more efficiently through verbal conferences. Taking time early in the semester to build community in the classroom through icebreakers, team/group activities, and collective/collaborative assignments can save time later in the semester because students will have networks of support upon which they can rely. While all students benefit from these personalized interactions, research suggests that Black and Latino men, who have historically low student success outcomes compared to White and female counterparts, benefit especially from relationship-centered instruction (Palacios, Wood, \& Harris, 2015; Wood \& Turner, 2011).

Create opportunities to practice critical self-reflection. The road to becoming a more equity-oriented educator may be long, but it is accomplished through many individual steps. The first step is committing to critical self-reflection that allows instructors to think critically about their own personal and professional experiences and to reflect on what is working, what needs changing, and what can be eliminated. Critical reflection helps instructors to see how equity might already be embedded in their practices and to see where practices can be adapted to better meet diverse student needs. The participants in this study all spoke about their own early educational experiences and how those influenced their current understanding of equity and educational inequities. Regardless of any external or departmental structures that may exist, instructors can pursue critical self-reflection independently at the starting point of their experiences with equity. 


\section{Recommendations for English Faculty Leaders}

This transitional period in California community colleges is an opportunity for substantial repayment of the educational debt owed to historically underserved and excluded groups (Ladson-Billings, 2006). This study illuminated how individual instructors' thinking and enacting of equity is inextricably tied to departmental discussions about equity and the ways various equity frameworks might be employed in a department. Consequently, faculty leadership at the department level is needed to best facilitate change. In distributive leadership and social justice frameworks, leaders are people who build the capacity in others to carry on and carry out the important work of dismantling systemic oppression and inequity (Boggs \& McPhail, 2016; Brown, 2004; Brown, 2006; Capper, Theoharis, \& Sebastian, 2006; Carrington \& Robinson, 2004; Cooper, 2009; Howard \& Navarro, 2016; Shields \& Mohan, 2008). Within a department, this work falls to faculty leaders who initiate and facilitate learning with colleagues in both formal and informal ways. Although a single definition of social justice in educational leadership has been elusive, constant factors are concern, care, and advocacy for diverse students who have experienced disproportionately negative academic outcomes (Boggs \& McPhail, 2016; Hytten \& Bettez, 2011; Shields \& Mohan, 2008). Building on this professional care and based on the findings of this study, I recommend that faculty leaders work within the department to define and 
discuss critical issues and to create structured, professional learning opportunities for instructors to practice critical self-reflection.

Define critical issues. Findings from this study suggest that faculty leaders should begin the department work by addressing critical issues that were raised by the participants, namely rigor, racial inequity, and identifying various equity frameworks already at work in the department. Examples of prominent equity frameworks are described in chapter two; these are AB705 and the completion agenda; acceleration; pragmatic equity-oriented practices; culturally relevant, culturally responsive, and culturally sustaining pedagogies; learning communities; and equity-mindedness. As time goes on, faculty leaders should facilitate identifying additional critical issues that will come up, especially as student success data is collected on the new placement methods and course pathways.

Create opportunities for critical self-reflection for faculty. Faculty leaders should also advocate for structures that allow for instructor and departmental critical reflection. One of the capacities crucial to social justice, equity, and inclusion is critical reflection, which combines critical inquiry with self-reflection to better understand one's own values, beliefs, biases, and assumptions (Brown, 2004; Brown, 2006; Capper, Theoharis, and Sebastian, 2006; Carrington \& Robinson, 2004; Howard \& Navarro, 2016; Ryan, 2006; Shields \& Mohan, 2008). Programs like communities of practice (Wenger, 2000), faculty interest groups, and campus teaching and learning 
centers can provide the space for instructors to reflect on their individual pedagogy as well as on their role in delineating department values and consequent practices related to pedagogy and curriculum.

\section{Recommendations for College Leaders}

In order to assure faculty that the college is indeed committed to improving equity for students and not just improving "throughput" as the equity discourse from the completion agenda suggests (Bailey et al., 2015), college administrators should support the faculty's autonomy to make decisions that are within their purview under shared governance, specifically curriculum and instruction. College leaders should also demonstrate their commitment by providing financial and other support to continued professional development for faculty and structured supports for students. Support for professional development may include travel funding for conferences, pay for adjunct instructors to participate in department workgroups, course release time for faculty taking on leadership roles, and funding to bring equity-oriented professionals to campus to lead workshops for faculty. Structured supports for students include programs and services that provide direct support to students and that act as complements to classroom instruction, such as writing centers, supplemental instruction, and embedded classroom tutors.

Recommendations for Pre-Service Training Programs for Writing Teachers 
In developmental education, major legislative, curricular, and instructional reforms are underway that forefront achieving equity as a central goal of higher education. The findings of this study suggest that taking time to intentionally consider the role of equity in education shapes how instructors perceive and enact equitable instructional practices. Pre-service training programs for writing teachers, such as Master's programs in Composition or Rhetoric, should intentionally adopt an equityorientation in their content, curriculum, and instruction. Students in these programs need to gain a broad view of the equity landscape, not just the pedagogical world of the classroom. With equity-oriented content and curriculum, teachers-in-training can develop an understanding of how systemic inequities, especially racial inequities, persist, and how they as teachers can disrupt that system using a variety of equity frameworks, tools, and student supports. In addition, coordinators and faculty in these programs must also adopt equity-oriented pedagogical practices themselves to support students from underserved populations who are enrolled in the program so that those students, who will go on to become teachers themselves, do not feel alienated by their own experiences in higher education.

\section{Recommendations for Further Study}

As AB705 is fully implemented and English departments make the transition to newly reimagined pathways, future research should revisit instructor perspectives on equity and equity-oriented practices. Linking this research to data on student outcomes 
in the college-level composition course can provide an added perspective on how well instructor perspectives align with program efficacy. Further research to explore the student experience in classrooms of equity-minded instructors, like the participants in this study, would provide rich data that would benefit English instruction at both developmental and transfer levels. Insight into both practices and the principles informing practices can help English faculty, instructional leaders, and department/program leaders to better understand the how and why behind teaching composition for social justice.

\section{Final Reflection}

As I look back at my growth as an educator and compositionist since I first began my graduate education in teaching writing, I am struck by the idea that even today, nearly twenty years later, my understanding of equity continues to evolve. Teaching writing is deeply rewarding work; while I love language and all its possibilities, it is the human interactions with students over the years that compels me to push myself to better serve my students. I remember all too well those moments in my own education when I realized that the content I was learning was not written for a multiracial, bicultural daughter of an immigrant. As an educator, I want my students to find themselves reflected in our classes and to see how powerfully they can contribute to the world. 
Understanding the views and practices of Amy, Jack, Judith, Leny, Rosina, and Scott is a lesson for all community college English instructors in both how and why adopting an equity-minded view of teaching is important. Instructors can benefit from seeing how equity-minded values are realized in classroom practices and assignments. Teaching adults academic writing, active reading, and critical thinking skills is an enormous responsibility that these instructors take seriously. Engaging in the critical discussions for transforming our work at NCCC has not been easy. As we move into the phase of full implementation, we are likely to experience more growing pains, but moving forward with a commitment to social justice in academia can provide the opportunity and framework for engaging in the department and college level critical reflection necessary to better serve our students. For developmental English teachers, working with vulnerable students demands a conscious, intentional, and culturally competent sense of ethical responsibility.

To have a clear direction and moral purpose in our work can drive us to improve ourselves, our teaching, and our actions with students and colleagues alike. But we also have to be willing to constantly reexamine our practices, our philosophies, and their impact on students. In the words of Jack:

I think it truly is as an amazing opportunity. I think this is a great opportunity for us...I think that us, faculty, we can come together and think how we're doing some really cool stuff. I think that we can talk about the books we want to use. I 
think we can talk about the assignments we want to use... But we have to look at ourselves and say, "Here's what I do, and here's what I don't do well." I wanna be in the thick of it because why else would I be here? Why else do people do this job? If you're not going to do the work and get in on it and be like, "How can we do this better?" and "what classes can we improve on?" or "what should we be adding that we're not adding?" I mean, we should be doing these things. That's the work that we're doing.

Indeed, it is the work all educators should be doing. 


\section{References}

AB705 (2018). Seymour-Campbell Student Success Act of 2012: matriculation:

assessment. Ch. 745, Sect. 78213 of Education Code (2017).

Bailey, M.J., \& Dynarski, S.M. (2011). Gains and gaps: Changing inequality in U.S. college entry and completion. (Working Paper No. 17633). Retrieved from National Bureau of Economic Research website:

\section{https://www.nber.org/papers/w17633}

Bailey, T.R., Smith Jaggars, S., \& Jenkins, D. (2015). Redesigning America's community colleges: A clearer path to student success. Cambridge, MA: Harvard University Press.

Bailey, T.R., Jeong, D.W., \& Cho, S.-W. (2010). Referral, enrollment, and completion in developmental education sequences in community colleges. Economics of Education Review, 29, 255-270.

Banks, J.A. (2004). Multicultural Education: Historical Development, Dimensions, and Practice. In J. A. Banks, \& C. A. M. Banks (Eds.), Handbook of research on multicultural education (2 ${ }^{\text {nd }}$ ed., pp. 3-29). San Francisco, CA: Jossey-Bass.

Bensimon, E.M. (2007). The underestimated significance of practitioner knowledge in the scholarship on student success. The Review of Higher Education, 30(4), 441469. DOI: https://doi.org/10.1353/rhe.2007.0032

Bensimon, E.M., Dowd, A.C., \& Witham, K. (2016). Five principles for enacting 
equity by design. Diversity and Democracy: Civic Learning for Shared Futures, 19(1). Retrieved from: https://www.aacu.org/diversitydemocracy/2016/winter Bensimon, E. M., \& Harris III, F. (2012). The mediational means of enacting equity mindedness among community college practitioners. In E. M. Bensimon \& L. E. Malcolm (Eds.), Confronting equity issues on campus: Implementing the equity scorecard in theory and practice. Sterling, VA: Stylus Publishing.

Bettinger, E.P., \& Long, B.T. (2006). The increasing use of adjunct instructors at public institutions: Are we hurting students? In R. G. Ehrenbert (Ed.), What's happening to public higher education (pp. 51-69). Westport, CT: Praeger.

Boggs, G.R., \& McPhail, C.J. (2016). Practical leadership in community colleges. Ch 5. Hoboken, NJ: Jossey-Bass. 81-107.

Bolden, R. (2011). Distributed leadership in organizations: A review of theory and research. International Journal of Management Reviews, 13, 251-269. doi:10.1111/j.1468-2370.2011.00306.x

Bonilla-Silva, E. (2006). Racism without racists: Color-blind racism and the persistence of racial inequality in the United States. Rowman \& Littlefield Publishers.

Blumenstyk, G. (2015). American higher education in crisis?: What everyone needs to know. New York, NY: Oxford Press.

Brown, K.M. (2004). Leadership for social justice and equity: Weaving a 
transformative framework and pedagogy. Educational Administration Quarterly, $40(1), 77-108$.

Brown, K.M. (2006). Social justice education for preservice leaders: Evaluating transformative learning strategies. Equity \& Excellence in Education 38(2): 155167. doi:10.1080/10665680590935133

The California Acceleration Project. https://accelerationproject.org

Capper, C.A., Theoharis, G., \& Sebastian, J. (2006). Toward a framework for preparing leaders for social justice. Journal of Educational Administration, 44(3), 209224.

Carrington, S. and Robinson, R. (2004). A case study of inclusive school development: A journey of learning. The International Journal of Inclusive Education $8(2): 141-153$.

Charmaz, K. (2014). Constructing grounded theory (2nd ed). Los Angeles, CA: Sage.

Cho, S.-W., Kopko, E., Jenkins, D., \& Smith Jaggars, S. S. (2012). New evidence of success for community college remedial English students: Tracking the outcomes of students in the Accelerated Learning Program (ALP) (CCRC Working Paper No. 53). New York, NY: Community College Research Center, Columbia University.

Coleman, D. (2015). Replicating the accelerated learning program: Updated findings. Charlotte, NC: Center for Applied Research, Central Piedmont Community 
College.

Cooper, C.W. (2009). Performing cultural work in demographically changing schools: Implications for expanding transformative leadership frameworks. Educational Administration Quarterly, 45(5), 694-724. doi: 10.1177/0013161X09341639

Conference on College Composition and Communication (1974, Fall). Students' right to their own language (CCC vol.XXV). Anaheim, CA: CCC.

Cuellar Mejia, M., Rodriguez, O., \& Johnson, H. (2016). Preparing students for success in California's community colleges. San Francisco, CA: Public Policy Institute of California. Retrieved from https://www.ppic.org/content/pubs/report/R 1116MMR.pdf

Cuellar Mejia, M., Rodriguez, O., Johnson, H., \& Brooks, B. (2018). Reforming English pathways at California's community colleges. San Francisco, CA: Public Policy Institute of California. Retrieved from https://www.ppic.org/wpcontent/uploads/r-0217mcr.pdf

Darling-Hammond, L. (2010). The flat world and education: How America's commitment to equity will determine our future. New York, NY: Teachers College Press.

Delpit, L. (1995). Other people's children: Cultural conflict in the classroom. New York, NY: New Press.

Denzin, N.K., \& Lincoln, Y.S. (2013). Collecting and interpreting qualitative 
materials. (4 ${ }^{\text {th }}$ ed.). Los Angeles, CA: Sage.

Eagan, K.M. \& Jaeger, A.J. (2009). Effects of exposure to part-time faculty on community college transfer. Research in Higher Education, 50, 168.

\section{https://doi. org/10.1007/s11162-008-9113-8.}

Francis, C. (2018). Academic rigor in the college classroom: Two federal commissions strive to define rigor in the past 70 years. New Directions for Higher Education, 181, 25-34. DOI: $10.1002 / \mathrm{hc} .20268$

Freire, P. (1972). Pedagogy of the Oppressed. New York, NY: Herder \& Herder

Gay, G. (2010). Culturally responsive teaching: Theory, research, and practice. Teachers College Press.

Goen-Salter, S. \& Gillotte-Tropp, H. (2003). Integrating reading and writing: A response to the basic writing "crisis." Journal of Basic Writing, 22(2), 90-113.

Graham, C. \& Essex, C. (2001). Defining and ensuring academic rigor in online and on-campus courses: Instructor perspectives. Annual proceedings of selected research and development: Practice papers presented at the national convention of the association for educational communications and technology, (1)2, 330337.

Greenfield, L. (2011). The "standard English" fairy tale: A rhetorical analysis of racist pedagogies and commonplace assumptions about language diversity. In 
L. Greenfield \& K. Rowan (Eds.), Writing centers and the New Racism: A call for sustainable dialogue and change (pp. 33-60). University Press of Colorado. Retrieved from http://www.jstor.org/stable/j.ctt4cgk6s.6

Grubb, W.N., \& Gabriner, R. (2013). Basic skills education in community colleges: Inside and outside of classrooms. New York, NY: Routledge.

Hartwell, P. (1985). Grammar, grammars, and the teaching of grammar. College English, 47(2).

Hayward, C. \& Willett, T. (2014). Acceleration effects of curricular redesign in the California Acceleration Project. Berkeley, CA: The Research and Planning Group for California Community Colleges.

Hodara, M., \& Smith Jaggars, S. (2014). An Examination of the Impact of Accelerating Community College Students' Progression through Developmental Education. Journal of Higher Education, 85(2), 246-276.

hooks, b. (1994). Teaching to Transgress. New York, NY: Routledge.

Horning, A.S. \& Kraemer, E.W. (2013). Reconnecting reading and writing. Anderson, SC: Parlor.

Howard, T.C. \& Navarro, O. (2016). Critical race theory 20 years later: Where do we go from here? Urban Education, 51, (3), 253-273.

Hytten, K. \& Bettez, S.C. (2011). Understanding education for social justice. Educational Foundations. Winter-Spring. 7-24. 
Jaggars, S. S., Hodara, M., Cho, S.-W., \& Xu, D. (2015). Three accelerated developmental education programs: Features, student outcomes, and implications. Community College Review, 43(1), 3-26.

Jenkins, D., Speroni, C., Belfield, C., Jaggars, S. S., \& Edgecombe, N. (2010). A Model for accelerating academic success of community college remedial English students: Is the Accelerated Learning Program (ALP) effective and affordable? (CCRC Working Paper No. 21). New York, NY: Community College Research Center, Columbia University.

Karen, D. \& Dougherty, K.J. (2005). Necessary but not sufficient: Higher education as a strategy of social mobility. In G. Orfield, P. Marin, \& C.L. Horn, (Eds.), Higher education and the color line: College access, racial equality, and social change (pp. 33-57). Cambridge, MA: Harvard Press.

Keller, D. (2013). Chasing literacy: Reading and writing in an age of acceleration. Logan, UT: Utah State UP.

Laden, B. V. (2000). The Puente Project: Socializing and Mentoring Latino Community College Students. Academic Exchange Quarterly, (2), 90-99. Retrieved from http://search.ebscohost.com.jpllnet.sfsu.edu/login.aspx?direct=true\&AuthType=i p,cookie,url,uid\&db=eric\&AN=EJ677361\& site=ehost-live

Ladson-Billings, G. (1995). Toward a theory of culturally relevant pedagogy. American Education Research Journal, 32(3), 465-491. 
Majors, Y.J. \& Ansari, S. (2006). A multivoiced response to the call for an equitybased framework. Teachers College Record, 108(14), 190-210. Retrieved from https://www.tcrecord.org/library

Merriam, S.B. (1998). Qualitative research and case study applications in education. San Francisco, CA: Jossey-Bass.

Miles, M.B., Huberman, M.A., \& Saldaña, J. (2014). Qualitative data analysis: A methods sourcebook, $3^{\text {rd }}$ ed. Los Angeles, CA: Sage.

Moore, C., Offenstein, J., \& Shulock, N. (2011). Consequences of neglect: Performance trends in Callfornia higher education. Sacramento: CSU, Sacramento, Institute for Higher Education Leadership and Policy.

Moss, B.G., Kelcey, B., \& Showers, N. (2014). Does classroom composition matter?: College classrooms as moderators of developmental education effectiveness. Community College Review. 42(3), 201-220.

Nieto, S. (1992). Affirming diversity: The sociopolitical context of multicultural education. White Plains, NY: Longman.

Palacios, A., Wood, J.L., \& Harris III, F. (2015). Mexicano male students' engagement with faculty in the community college. In D. Mitchell Jr., K.M. Soria, E.A. Daniele, and J.A. Gipson's (Eds.) Student involvement \& academic outcomes: Implications for diverse student populations. New York, NY: Peter Lang. 185200. 
Paris, D. (2012). Culturally sustaining pedagogy: A needed change in stance, terminology, and practice. Educational Researcher, 41(3), 93-97. DOI: $10.3102 / 0013189 \times 12441244$

The Puente Project. (2019). Puente Success Data. Retrieved from https://puente.berkelev .edu/content/puente-success-data

The Puente Project. https://www.thepuenteproject.org/community-college-programs Rendón, L.I. (1994). Validating culturally diverse students: Toward a new model of learning and student development. Innovative higher education, 19(1), 33-51.

Rendón, L.I. (2002). Community college Puente: A validating model of education. Educational policy, 16(4), 642-667.

Rendón, L.I. (2014). Sentipensante pedagogy: Educating for wholeness, social justice and liberation. Sterling, VA: Stylus.

Rodriguez, O., Cuellar Mejia, M., \& Johnson, H. (2016). Determining college readiness in California's community colleges. San Francisco, CA: Public Policy Institute of California. Retrieved from https://www.ppic.org/content/pubs/report/R_11160RR.pdf

Rose, D. (2000). Walking the walk: Universal design on the web. Center for Applied Special Technology, 15, 45-49. doi: https://doi-org.jpllnet.sfsu.edu/10.1177/016264340001500307

Rose, D., Harbour, W.S., Johnston, C.S., Daley, S.G., \& Abarbanell, L. (2006). 
Universal design for learning in postsecondary education: Reflections on principles and their application. Journal of Postsecondary Education and Disability, 19(2), 135-151.

Rose, D.H. \& Meyer, A. (2002). Teaching every student in the digital age. Universal Design for Learning. Alexandria, VA: Association for Supervision and Curriculum Development.

Ryan, J. (2006). Inclusive leadership and social justice for schools. Leadership and Policy in Schools (2006), 5 (1) 3-17.

Scott-Clayton, J., \& Rodriguez, O. (2015). Development, discouragement, or diversion? New evidence on the effects of college remediation policy. Education Finance and Policy, 10(1), 4-45.

Schnee, E. (2008). "In the real world no one drops their standards for you": Academic rigor in a college worker education program. Equity \& Excellence in Education, 4I(1), 62-80. DOI: 10.1080/10665680701764502

Schnee, E. (2014). “A foundation for something bigger": Community college students' experience of remediation in the context of a learning community. Community College Review; Raleigh, 42(3), 242-261.

Shields, C.M. \& Mohan, E.J. (2008). High quality education for all students: Putting social justice at its heart. Teacher Development, 12(4), 289-300.

Southard, A. H., \& Clay, J. K. (2004). Measuring the effectiveness of developmental 
writing courses. Community College Review; Raleigh, 32(2), 39-50.

Student Success Scorecard. (2018). The California Community College Chancellors Office. Retrieved from http://scorecard.cccco.edu

Valenzuela, A. (1999). Subtractive schooling: Issues of caring in education of USMexican youth. Albany, NY: State University of New York Press.

Wenger, E. (2000). Communities of practice and social learning systems. Sage Journal, 7(2), 225-246. htttos://doi.org/10.1177/135050840072002

Witham, K., Malcom-Piqueux, L.E., Dowd, A.C., \& Bensimon, E.M. (2015). America's unmet promise: The imperative for equity in higher education. Washington, D.C.: Association of American Colleges and Universities.

Wood, J.L., Harris III, F., \& White, K. (2015). Teaching men of color in the community college: A guidebook. San Diego State University. San Diego, CA:

Montezuma.

Wood, J.L. \& Turner, C.S. (2011). Black males and the community college: Student perspectives on faculty and academic success. Community College Journal of Research and Practice, 35: 135-151. DOI: 10.1080/10668926.2010.526052.

Xu, D. (2016). Assistance or obstacle? The impact of different levels of English developmental education on underprepared students in community colleges. Educational Researcher, 45(9), 496-507. 
Yin, R.K. (2018). Case study research and applications: Design and methods. (6 $6^{\text {th }}$ ed).

Los Angeles, CA: Sage. 


\title{
Appendices
}

\author{
Appendix A \\ Invitation to participate - recruitment letter
}

Dear

As you may know, I am currently a doctoral candidate at San Francisco State University in the Educational Leadership Program. I am conducting research on community college English instructors' equity-oriented practices and pedagogy in teaching composition in developmental English classes. I am inviting you to participate because you regularly teach developmental English at North Coast Community College.

I am seeking participants who identify equity in education as a personal professional value. Ideal participants would have at least two years' experience teaching English at the developmental level and teach or have taught a developmental English course in Summer 2018 or Fall 2018.

Participation in this research includes completing a short questionnaire, participating in two interviews, sharing course materials (such as syllabi, assignment prompts, reading lists, grading rubrics), and sharing an anonymized sample of student writing with your feedback.

If you agree to participate, I will contact you by email or phone to schedule both interviews and to send you the questionnaire, which can be completed any time prior to the first interview. Interviews will be held at a location that is both convenient to you and offers privacy, such as a private room at a local library or an office. The interviews will each take 60-90 minutes, and I will audio record the interview to make sure I understand what you have said. Your total time commitment will be 3-5 hours.

If you have any questions about the study or would like to participate in the research, I can be reached at (XXX) XXX-XXXX or scavales@mail.sfsu.edu.

Sheryl Cavales Doolan

EDDL doctoral candidate

San Francisco State University 


\section{Appendix B}

\section{First Interview Question Bank}

1. What do you like best about teaching developmental English?

2. You've indicated that you value equity in education. Can you explain what that means to you as an English instructor?

3. How did you come to hold this value?

4. In what ways do you communicate your equity-orientation to your students?

5. Overall, what does it mean to you to promote equity in the classroom?

6. Can you describe an assignment or teaching practice that you think supports equitable outcomes for the diverse range of students in your developmental English class?

7. How do you think your belief in equity might manifest in your class? For example, if I were to read your syllabus, how would I see your value of equity represented in that artifact?

8. Describe a student's typical process for writing a formal essay. (That is, how many drafts, from whom do they receive feedback, at what stages, etc.)

Follow-up: How do you give feedback to students? Do you vary your feedback practices for students with different needs?

9. Can you tell me about your grading/assessment process of essays?

Possible follow-ups: Do you use a grading rubric? How do you mark final papers?

Do you offer the possibility of rewriting?

10. America's Unmet Promise: The Imperative for Equity in Higher Education (Witham et al., 2015) argues that any reform in higher education must begin with an awareness of the ways many groups have been excluded from educational opportunities or marginalized in educational institutions. The authors write, "Simply put, achieving equality in outcomes does not mean - in fact cannot mean treating all students as though they are the same. Rather, [equity-focused] policies and practices in higher education recognize and accommodate differences in 
students' aspirations, life circumstances, ways of engaging in learning and participating in college, and identities as learners and students" (p.31).

What does this mean to you? How does it relate to your work as a developmental English instructor?

11. In the same report, the authors write, "Importantly, equitable practices or policies may introduce unequal distributions of resources....Though ostensibly unequal, these practices are considered equitable because they are necessary to produce equality in some outcome like access to or success in higher education" (Witham, et al., 2014, p. 28).

Can you tell me about a regular classroom practice you do that might illustrate an "unequal distribution of resources"? For what outcome?

12. Think about how your teaching in developmental classes has changed over time. What do you think is the most significant change you've made as an instructor in the way you teach developmental classes?

13. Once AB705 is implemented, developmental classes will be disappearing, and those students who would have been placed in developmental classes will now enroll immediately into college-level English. Based on your experience of teaching developmental courses, what advice would you share with instructors of collegelevel English to create practices that will promote equity and support the increasingly diverse student population? 


\section{Appendix C}

Representative sample of question bank for Second Interview Protocol. Nota bene: questions for the second interview were tailored for each participant based on responses to first interview questions. The questions included here represent a sample of typical questions asked of participants during the second interview.

1. Tell me about a student in your developmental class this semester who struggled but was successful. What worked with this student?

2. When we last spoke, you talked about an assignment that you thought supported equitable outcomes for the diverse range of students in your developmental English class. Can you tell me more about the Critical SelfReflection essay prompt? Can you tell me about how you wrote this? Let's look at some of the specific language.

How successful was this assignment? What students did well with this? What students found it more challenging?

3. In the last interview, when you talked about the writing process for your students, you mentioned writing conferences. Can you tell me more about your conferences?

What is the proportion of written feedback to face-to-face feedback? Why? How do ELLs respond to that kind of feedback?

Do you think your preferred form of feedback is sustainable for most instructors?

4. Can you describe a time when you experienced inequity as a student, or when you first understood disparities in educational experiences? How have your personal experiences shaped your values?

5. In our last interview, you mentioned that after getting tenure, you felt you'd gotten braver with being vulnerable in the classroom. How might we support "vulnerable" instructors better? 
6. Department discussions of rigor came up in our first interview. How do you define 'rigor'? How do you think we should be defining rigor?

You mentioned before that some folks are afraid that "rushing" students through the pathway requires 'dumbing down' curriculum or lowering standards and passing students who shouldn't pass. How do you think we can maintain rigor and standards?

7. Related to the above question, other interviews suggest that this fear of equity-driven work might be related more to fear of more work or harder work. How can we support all students in a sustainable way for instructors?

8. In "Five Principles for Enacting Equity by Design", the authors extend the argument above, describing a paradigm difference that equity-minded educators have. They write, "... [P]ractitioners taking the traditional approach to student success may ask: What does this student lack and how can he/she be remediated? From an equity-minded standpoint, the primary question is: Why are our practices failing to produce success for students of color?"

What does this mean to you? How would you describe your department's discussions about equity and student success in light of this paradigm difference?

9. At the end of our last interview, you described how your teaching of developmental English has changed over time. How has your teaching of college level classes changed?

10. Is there anything else you would like to share with me that I haven't asked about? 